\title{
Investor Protection, Risk Sharing and Inequality ${ }^{\not}$
}

\author{
A lessandra Bon..glioliy \\ Institute for E conomic A nalysis, C SIC
}

J anuary 29, 2007

\begin{abstract}
A bstract
This paper studies the relat ionship between investor protection, ..nancial risk sharing and income inequality. In the presence of market frictions, better protection makes invest ors more willing to take on entrepreneurial risk while lending to ..rms. This implies lower cost of external ..nance and better risk sharing between ..nanciers and entrepreneurs. Investor protection, by boosting the market for risk sharing plays the twofold role of encouraging agents to undertake risky enterprises and providing them with insurance. By increasing the number of risky projects, it raises income inequality. By extending insurance to more agents, it reduces it. A s a result, the relationship between the size of the market for risk sharing and income in equality is hump-shaped. Empirical evidence from a cross-section of sixty-eight countries, and a panel of ..fty countries over the period 1976-2000, supports the predictions of the model.

J EL Classi..cation: D31, E44, G30, 0 15, 016

Keywords: Income inequality, stock market development, ..nancial development, capital market frictions, investor protection, instrumental variables, dynamic panel data.
\end{abstract}

\footnotetext{
${ }^{x}$ thank for their useful comments: Philippe Aghion, Francesco Caselli, A mparo Castelló Climent, Giovanni Favara, Gino Gancia, N icola Gennaioli, J ohn Hassler, Ross Levine, Alexander Ludwig, Torsten Persson, Andrei Shleifer, J aume Ventura, Fabrizio Zilibotti and seminar participants at B anco de E spaña, Bocconi University, CREI, European Central B ank, IAE -CSIC, IIES, SIFR, U niversitaat van A msterdamTimbergen Institute, Universidad Carlos III de Madrid, Universitat Autonoma de Barcelona, University of Leicester, University of St. Andrews, U niversity of Warwick, the 2006 CEPR European Summer Symposium on International M acroeconomics, E NT ER J amboree 2004, "Economic G rowth and Distribution" 2004 conference, 2004 Annual M eeting of the Society for Economic Dynamics, 2004 European Winter Meeting of the Econometric Society, and ASSET Annual Conference 2004. A Il remaining errors are mine.
}

${ }^{y}$ Address: Institut d'A nalisi Economica, Campus UAB, 08193 B el laterra, B arcelona, Spain. E-mail: alessandra.bon..glioli@upf.edu 


\section{Introduction}

A recent literature on law and ..nance has shown that investor protection plays a signi..cant role in shaping the ..nancial structure of an economy, by axecting the relative weights of equity and debt in external ..nance (see A cemoglu and J ohnson, 2003 and La P orta et al., 1997 and 2006, among others). In particular, it is argued that measures aimed at improving transparency and disclosure of information to the shareholders, and the enforcement of their rights, reduce the costs of outside-..nance (see, for instance, Shleifer and Wolfenzon, 2002) and allow a better allocation of risk between ..nanciers and entrepreneurs (see Castro et al., 2004). Several works have recognized the importance of ..nancial development for enhancing macroeconomic performance, mainly as measured by G DP growth and productivity (see, Demirgüç-K unt and Levine, 2001 for a survey). However, this growing literature has not recognized that the changes in the risk-taking behavior of investors and ..rms, associated with better shareholder protection, may also axect income inequality.

This paper investigates the link between investor protection, risk sharing and income inequality, both theoretically and empirically. It proposes a simple model where investor protection promotes risk sharing between ...nanciers and entrepreneurs, thereby inducing more risk taking in the economy. B etter insurance on individual earnings and wider risk taking, in turn, axect income inequality in opposite ways. The relationships predicted by the model are then confronted with the data.

To formalize these ideas, I construct a general equilibrium two-period overlapping generations model where agents are risk averse and heterogeneous in their entrepreneurial ability. When young, agents face a choice between a safe and a risky technology, and entrepreneurial ability axects the probability of success in the risky project. Starting up a ..rm requires an initial investment, so that entrepreneurs may have to borrow capital. Financial contracts are designed to be optimal and incentive compatible, and may make risk sharing between investors and entrepreneurs possible to a certain degree. F inancial markets are subject to imperfections arising from the non-observability of output to ... nanciers, but measures of investor protection can be adopted to amend these frictions. In particular, by promoting transparency, investor protection makes it costly for entre preneurs to misreport their cash $\ddagger$ ow. ${ }^{1}$ For instance, this cost can be thought of as the extra-compensation an advisory ..rm charges to certify a falsi..ed book or to design ...nancial operations to hide revenues from outside ..nanciers. Better guarantees generate more con..dence among investors, thereby making them more willing to bear risk and insure the

\footnotetext{
${ }^{1}$ Also in Aghion et al. (2005), Castro et al. (2004) and Lacker and Weinberg (1989) does investor protection take the form of a hiding cost. In this paper, like in the two latter, the cost is proportional to the hidden amount, while in the ..rst, it equals a fraction of the initial investment.
} 
entrepreneurs through lending. In turn, investors can spread the individual risk by hol ding diversi..ed portfolios of risky activities. As a result, ...nancial systems with stronger investor protection provide entrepreneurs with higher degrees of risk sharing. F inally, I rule out wealth heterogeneity, so that all inequality is due to idiosyncratic factors (ability), ..nancial market conditions and income risk. Under these assumptions, better investor protection arects income inequality in three ways. (i) It improves risk sharing, thereby reducing income volatility for a given mass of agents operating the risky technology; (ii) it raises the share of the population choosing the risky option, and therefore being exposed to earning risk; and (iii) it increases the reward to ability. (i) tends to reduce inequality, while (ii) and (iii) raise it.

The main result of the paper is that income inequality is a hump-shaped function of investor protection and of the size of the market for ..nancial instruments that allow risk sharing (brieły, the market for risk sharing). A ny improvement upon a low level of investor protection increases risk taking more than risk sharing, thereby driving inequality up. However, when investor protection is suф ciently high - and the market for risk sharing is big enough - any further improvement axects more risk sharing than risk taking, hence reduces income inequality.

This theoretical result is derived in terms of the size of the market for risk sharing, which cannot be measured directly. It can be argued, though, that entrepreneurs bear more risk the more leveraged they are, and thus the market for risk sharing is bigger, the higher the weight of equity relative to debt in the capital structure. Therefore, to eval uate empirically the predictions of the model, I proxy the size of the market for risk sharing with the ratio of stock market capitalization over total credit to the private sector. In particular, I provide evidence from a cross-section of sixty-eight countries and a panel of ...ty countries, spanning from 1976 to 2000 , that: (1) there is a hump-shaped relationship between income inequality and the ratio of stock market capitalization over total credit to the private sector; and (2) the latter grows with investor protection.

The contribution of this paper is related to three main strands of literature. A cemoglu and J ohnson (2003), as well as La Porta et al. (1997, 1998, 1999, 2006), show that investor protection, and in general institutions aimed at contracting protection axect the ..nancial structure of an economy by promoting the development of stock markets, but have unclear exects on economic performance. None of these studies has considered income inequality.

M any papers (see Levine, 2005 for a survey) provide empirical evidence on the link between ..nancial development and macroeconomic performance in terms of GDP growth, investments and productivity. ${ }^{2}$ It is also shown that whether ...nancial markets are more

\footnotetext{
${ }^{2} \mathrm{All}$ these works account for the inłuence of the legal environment on ..nancial structure. In particular,
} 
stock- or debt-based does not seem to matter for macroeconomic performance, but no attention was paid to the exects of ..nancial structure on income distribution.

Theoretical contributions by A ghion and B olton (1997), Banerjee and Newman (1993), Galor and Zeira (1993), Greenwood and J ovanovic (1990), and Piketty (1997), among others, have proposed explanations for the relationship between ..nancial development, inequality and growth. In most of these models, income inequality originates from heterogeneity in the initial wealth distribution, paired with credit market frictions. As the poorest are subject to credit constraints, they are prevented from making ec cient investments in the most productive activities. ${ }^{3}$ Over time, capital accumulation determines the dynamics of wealth and income. I depart from this approach in two main respects. First, I shift the focus from ..nancial development, broadly de.ned as the overall availability of external ..nance to the private sector, to the development of the market for instruments that allow agents not only to raise external ..nance but also to share risks at the same time. Second, I consider a dixerent source of ex-ante heterogen eity (entrepreneurial ability), and propose a new mechanism translating dixerences in ability into income inequality that is independent of wealth accumulation. In the present paper, heterogeneity in productivity, the extent of risk sharing and the size of the risky sector ultimately determine the income distribution.

There are, to my knowledge, only two empirical assessments of the relationship betwen ..nancial development and income inequality (Clarke et al., 2006 and Beck et al., 2006). As the theoretical works above, these papers are interested in the exects of overall external ..nance availability on income inequality, and both ..nd evidence of a negative relationship. My contribution focuses explicitly on the impact of a particular form of external, risksharing, ..nance on income inequality. Therefore, instead of taking a general measure of ..nancial depth as a regressor for income inequality, I use the size of the stock market relative to total credit to the private sector, that seems well suited to account for the degree of risk sharing allowed by a ...nancial system. Not only are my empirical results consistent with the previous evidence on the negative exect of ..nancial depth on income inequality, but they also provide a novel contribution by emphasizing the opposite role of equity-like ...nance in raising inequality.

The remainder of the paper is organized as follows. Section 2 presents the model and its solution in partial equilibrium (a small open economy). In section 3, I study analytically and by means of numerical solution how income inequality varies with investor protection

..nancial variables are instrumented with legal origins, which A cemoglu and J ohnson (2003) and La Porta et al. $(1997,1998,1999,2006)$ used as instruments for contracting protection.

${ }^{3}$ T he credit constraint can derive from the non-observability of physical output as in Banerjee and Newman (1992) and Galor and Zeira (1993), or exort as in Aghion and Bolton (1997) and Piketty (1997). 
and the size of the market for risk sharing. I show in the appendix that the main results hold in general equilibrium (a closed economy). Section 4 shows that empirical evidence from a cross-section of sixty-eight countries and a panel of ...fty countries over the period 1976-2000 supports the main results of the model. Section 5 concludes.

\section{The model}

\subsection{Set up}

The model economy is populated by two-period overlapping generations of risk-averse agents. There is no population growth and the measure of each cohort is normalized to one. For simplicity, preferences are represented by the following utility function:

$$
U_{t}=\log \left(c_{t}\right)+\beta \log \left(c_{t+1}\right) .
$$

Second-period utility is discounted at the rate $\beta 2(0,1)$.

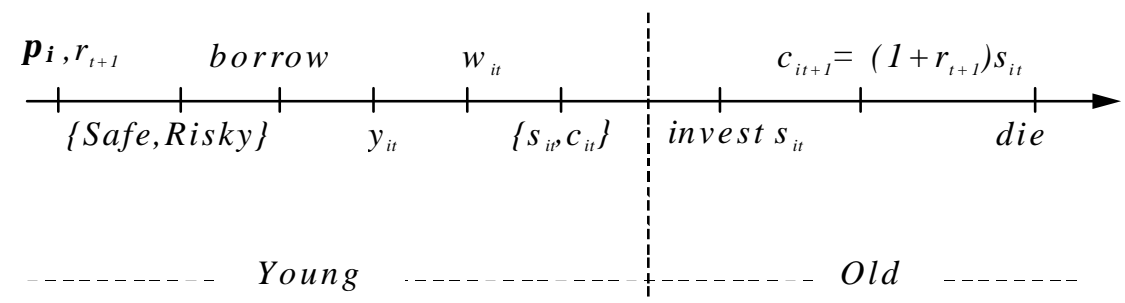

Figure 1: Timing of the model

At any time $t$, each young agent in ability group $i$ is born with no wealth and ability $\pi_{i} 2[0,1]$, drawn from distribution $G(\pi)$. Each group has a density $g(\pi)$ of individuals. In the ..rst period, agents work as self-employed entrepreneurs producing an intermediate good, and allocate their income among consumption and savings, $s(\phi$. When old, they invest their savings and consume all the returns before dying. When investing, they can choose between safe loans, yiel ding a return $r_{t+1}$, and portfolios of risky assets. There are no bequests.

\subsubsection{Intermediate goods sector}

Two production processes are available to each young agent: a safe and a risky one. Both technologies require a ..xed unit investment. In line with empirical ..ndings, I assume that the risky activity, if successful, has higher returns than the safe oneand that the probability 
of success depends on the ability of the entrepreneur. ${ }^{4}$ For simplicity, and without much loss of generality, I assume that ability only axects the probability of success and not the payous. ${ }^{5}$ In particular, production is given by:

$$
x_{i t}=\begin{array}{llll}
\gtrless & B & & \text { for } i \text { running Safe technology } \\
\gtrless & A & \text { with prob. } \pi_{i} & \text { for } i \text { running Risky technology, }
\end{array}
$$

where $B<A, \varphi 2(0,1)$ and success is i.i.d. within each group. It follows that there is no

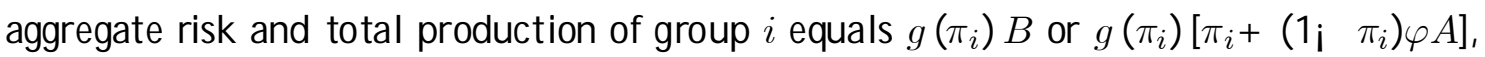
depending on the technology, safe or risky, in use. ${ }^{6}$

\subsubsection{F inal good sector}

A homogeneous ..nal good $Y$, used for consumption and investment, is produced by competitive ..rms using capital and intermediate goods. The intermediate goods produced by all types of agents are perfect substitutes in production. The aggregate technology has the following Cobb-Douglas form:

$$
Y_{t}=K_{Y t}^{\alpha} X_{t}^{l_{\mathrm{i}} \alpha}
$$

where $X_{t}$ is the total amount of intermediate goods, with a unit price of $\chi_{t}, K_{Y t}$ is the amount of capital employed in the ..nal good sector and $\alpha 2(0,1)$ is its share of production. $Y_{t}$ is the numeraire.

\subsubsection{Financial sector}

Firms in both the ..nal and the intermediate good sectors need to borrow capital from the old in order to produce. Information about technology $(A, B, \varphi, \alpha)$, individual ability $\left(\pi_{i}\right)$, and technological choice is public, but outside ..nanciers cannot observe the outcome of risky activities, $x_{i t}$.

The..nancial contract is modeled as follows. Upon receiving capital, each ..rm commits to pay, after production, shares $\theta_{t}^{h}$ and $\theta_{t}^{l}$ of its cash $\ddagger$ ow in case of success and failure,

\footnotetext{
${ }^{4}$ See Schiller and Crewson (1997), and Fairly and R obb (2003) for empirical studies on the determinants of entrepreneurial success, mainly among small ..rms.

${ }^{5} \mathrm{Ability}$ can be considered as playing a twofold role. It enhances the chance of succeeding in risky enterprises, as assumed in the model. But it may also raise productivity regardless of the riskiness of projects. Introducing this second exect into the model would not axect the results.

${ }^{6}$ For studies on the relationship between inequal ity, risk sharing and asset prices in presence of aggregate risk, see among others Constantinides and Duф̣ e (1996) and Storesletten et al. (2006).
} 
respectively. Final good producers and young entrepreneurs using the safe technology are not subject to any risk, nor information asymmetry, so that they will repay a ..xed amount for each unit of capital, corresponding to the safe interest rate, $r_{t}$. The repayment schedule facing young risky entrepreneurs is dixerent. Once production has occurred, unlucky entrepreneurs of type $i$ can only return the promised amount $\theta_{i t}^{l} x_{i t}^{l} \chi_{t}$. Successful entrepreneurs, instead, may misreport their realization of $x_{i t}$ and pay $\theta_{i t}^{l} x_{i t}^{l} \chi_{t}$, pretending to be in the bad state. However, I assume that measures of investor protection make misreporting costly. For every unit of hidden cash ¥ow, the entrepreneur incurs a cost $p 2[0,1]$. Since both ability and technology are common knowledge, either the entire amount ${ }^{\mathrm{i}} x_{i t}^{h}{ }_{i}^{l} x_{i t}{ }^{\Phi}$ or nothing is hidden, so that the payo from misreporting is ${ }^{\mathrm{i}} x_{i t}^{h} \mathbf{i}$ $\theta_{i t}^{l} x_{i t}^{l} \chi_{t} \mathbf{i} \quad p^{\mathbf{i}} x_{i t}^{h} \mathbf{i} \quad x_{i t}^{l} \chi_{t}$. Truth-telling is rational as long as its value is at least equal to that of misreporting. Therefore, the ..nancial contract ${ }_{\theta_{i t}^{h}}, \theta_{i t}^{l}$ must satisfy the incentive compatibility (IC) constraint:

$$
v^{\mathrm{h}^{3}} 1_{\mathbf{i}} \theta_{i t}^{h} x_{i t}^{h} \chi_{t}, r_{t+1}, v^{\mathrm{h}^{3}} x_{i t}^{h} \mathbf{i} \theta_{i t}^{l} x_{i t}^{l} \chi_{t} \mathbf{i} p^{3} x_{i t}^{h} \mathbf{i} x_{i t}^{l} \chi_{t}, r_{t+1},
$$

where $v\left[w_{t}, r_{t+1}\right]$ is the indirect utility of a young agent with a given income $w_{t}$ and facing an interest rate $r_{t+1}$ when old.

F inancial contracts are set to maximize theagents' expected indirect utility, $V_{i t}$, subject to the IC constraint and the outsiders' participation constraint. The latter requires that old agents be indixerent between lending to all ..rms of group-i, and lending to safe ..rms. Thus, the payous from the risky technology are determined as the solution to the optimal ..nancial contract problem:

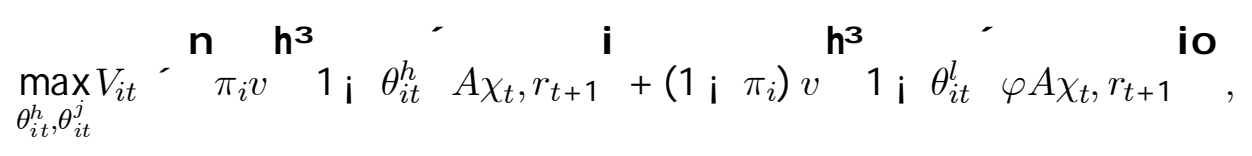

subject to the incentive compatibility constraint:

$$
v^{\mathrm{h}^{3}} 1 \mathbf{i} \theta_{i t}^{h} A \chi_{t}, r_{t+1}, v^{\mathrm{h}^{3}} 1 \mathbf{i} \varphi \theta_{i t}^{l} A \chi_{t} \mathbf{i} p(1 \mathbf{i} \varphi) A \chi_{t}, r_{t+1},
$$

and the old's participation constraint:

$$
\pi_{i} \theta_{i t}^{h} A \chi_{t}+\left(1_{\mathbf{i}} \pi_{i}\right) \theta_{i t}^{l} \varphi A \chi_{t}=r_{t}
$$

Note that a pooled portfolio of loans to the i.i.d. ..rms of group $i$ yields the LHS of (PC) with certainty, so that the old face no uncertainty. ${ }^{7}$

\footnotetext{
${ }^{7}$ It follows that the participation constraint is the same as in the case of risk-neutral ..nanciers with a
} 


\subsubsection{Equilibrium}

Firms in the ..nal good sector are perfectly competitive and maximize pro..ts taking prices $\left(r_{t}, \chi_{t}\right)$ as given. Each young agent from group $i$ has perfect foresight and chooses how much to save, $s(\phi$, and the technology to use (safe or risky), to maximize her expected utility. Thus, each of them solves the following program:

$$
\max _{\text {T2f Safe,Riskyg }} V_{i t}^{T}
$$

where

$$
\begin{aligned}
V_{i t}^{\text {Safe }} & =v\left(B \chi_{t} \mathbf{i} r_{t}, r_{t+1}\right) \quad \mathbf{i} \quad \mathbf{h}^{3}, \\
V_{i t}^{\text {Risky }} & =\pi_{i} v \quad 1 \mathbf{i} \theta_{i t}^{h} A \chi_{t}, r_{t+1}+\left(1 \mathbf{i} \pi_{i}\right) v^{\prime} \quad \theta_{i t}^{l} \varphi A \chi_{t}, r_{t+1} \\
v\left(w_{i t}, r_{t+1}\right) & =\log \left[w_{i t} \mathbf{i} s\left(w_{i t}, r_{t+1}\right)\right]+\beta \log \left[\left(1+r_{t+1}\right) s\left(w_{i t}, r_{t+1}\right)\right] \\
s\left(w_{i t}, r_{t+1}\right) & =\arg \max _{s_{i t}} \log \left(w_{i t} \mathbf{i} s_{i t}\right)+\beta \log \left[\left(1+r_{t+1}\right) s_{i t}\right] \mathbf{g} .
\end{aligned}
$$

Here, $w_{i t}$ is realized income, i.e., $B \chi_{t} \mathbf{i} r_{t}$ in case the safe technology is chosen, otherwise $\mathrm{i}_{1} \mathrm{i}_{i t}^{h} A \chi_{t}$ and ${ }^{\mathrm{i}} 1_{\mathrm{i}} \theta_{i t}^{l} \varphi A \chi_{t}$ in the good and bad state respectively. In other words, young entrepreneurs choose technology, given their individual ability $\pi_{i}$, factor prices $r_{t}$ and $\chi_{t}$, and the optimal ..nancial contract $\mathrm{f} \theta_{i t}^{l}, \theta_{i t}^{h} \mathrm{~g}$ which solves $(P 1)$.

To state the mechanism of the model in the clearest way, I ..rst assume this to be a small open economy. ${ }^{8}$ B oth capital and intermediate goods are internationally traded, so that $r_{t}$ and $\chi_{t}$ are exogenously given from the world markets, while the ..nal good $Y$ is non traded. ${ }^{9}$ A ssuming that prices $(r, \chi$ and $p)$ are constant, the economy is always in a steady-state and I can drop all the time indexes. It follows that aggregate domestic demand for the...nal good is $Y^{D}=(1+r){ }_{0}^{\mathrm{R}_{1}} s(\pi) g(\pi) d(\pi)+{ }_{0} w(\pi) g(\pi) d(\pi)$.

De..nition Given the interest rate $r$, the intermediate good price $\chi$, and the misreporting cost $p$, the equilibrium for this small open economy is de..ned as the set of savings, technological choices and ..nancial contracts $\mathrm{f}_{i}, T_{i}, \theta_{i}^{l}, \theta_{i}^{h}{ }_{i 2[0,1]^{\prime}}$ such that each agent in group $i$ solves (P1) -(P2); and the factor employments $\mathrm{f} K_{Y}, \quad X g$ that maximize pro..ts in the ..nal good sector.

For simplicity, I assume that $\varphi A<\frac{r}{\chi}<B<A$. This implies that both safe and

\footnotetext{
single type $i$ borrower.

${ }^{8}$ In the appendix, I endogenize the interest rate and the price of the intermediate good, and show that the main results continue to hold.

${ }^{9}$ This assumption is immaterial, since factor prices are equalized everywhere.
} 
risky intermediate projects are run in equilibrium; and when investor protection is absent, nobody chooses the risky technology. ${ }^{10}$

\subsection{Solution}

\subsubsection{Final good sector}

Pro..t maximization by competitive ..rms in the ..nal good sector yields the following demand functions for capital and intermediates: $K_{Y}=\alpha \frac{Y}{r}$ and $X=\left(1_{i} \alpha\right) \frac{Y}{\chi}$. Market clearing requires $Y=Y^{D}$.

\subsubsection{Young agents}

Due to log-utility, the optimal saving function of each young agent is simply a constant fraction $(1+\beta)^{i}{ }^{1}$ of her earnings. To solve for the optimal occupational choice $(P 2)$, an agent born in group $i$ needs to know the payous from the risky technology. Therefore, I proceed backwards. F irst, I derive the optimal ..nancial contracts $\stackrel{C}{C}_{i}^{h}, \theta_{i}^{l}{ }_{i 2[0,1]}^{\underline{a}}$ from $(P 1)$, under both perfect and imperfect investor protection. Then, I characterize the occupational choice, $f T_{i} g_{i 2[0,1]}$, given the optimal payous. Finally, I show how the equilibrium is axected by investor protection.

Optimal ..nancial contract: eф cient markets, $p=1$

In this case, the payo a from hiding cash fow equals earnings in the bad state, ${ }^{\mathrm{i}} 1_{\mathrm{i}} \theta_{i}^{l}{ }^{\phi} \chi x_{i}^{l}$. This means that there is no incentive for entrepreneurs to misreport, so that investors can act as if they had perfect information about $x_{i}$. Having a state-invariant income is the ..rst best for risk-averse entrepreneurs. Since outside ..nanciers behave as if they were riskneutral and perfectly informed, they are willing to provide insiders with full insurance, given that the expected return equals the safe rate. A nalytically, the ..rst-order conditions for $(P 1)$ subject to $(P C)$ require:

$$
\begin{aligned}
v_{h}^{0} & =v_{l}^{0} \quad \text { and } \\
1 \mathbf{i} \theta_{i}^{h} & =\left[\pi_{i}+\left(1 ; \pi_{i}\right) \varphi\right] \mathbf{i} \frac{r}{A \chi},
\end{aligned}
$$

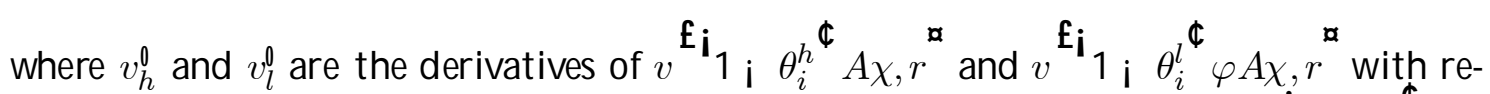
spect to $\theta_{i}^{h}$ and $\theta_{i}^{l}$, respectively. This means that ( $I C$ Q $)$ holds with equality and ${ }^{\mathrm{i}} 1_{\mathrm{i}} \theta_{i}^{h}{ }^{\phi} A \chi=$ $\mathrm{i}_{1} \mathrm{i} \theta_{i}^{l} \varphi A \chi$ (i.e., earnings of entrepreneurs are state invariant: $w_{i}^{h}=w_{i}^{l}$ ).

\footnotetext{
${ }^{10} \mathrm{~T}$ his assumption also rules out risky debt. However, it can be shown that removing this restriction would not have any considerable eaect on the results.
} 
Optimal ..nancial contract: general case, $0<p<1$

If investor protection is not perfect, state invariant earnings are not incentive compatible: entrepreneurs in the good state would be tempted to misreport $x_{i}$ and enjoy the higher utility given by earnings ${ }^{i} 1_{\mathbf{i}} \varphi \theta_{i t}^{l} A \chi_{\mathbf{i}} \quad p\left(1_{\mathbf{i}} \varphi\right) A \chi$. Investors are aware of this and hence account for it when determining the repayments. In other words, both ( $I C Q$ and $(P C)$ must hold with equality, so that

$$
\begin{aligned}
& w_{i}^{l}={ }_{3}^{3} 1 \mathrm{i} \theta_{i}^{l}, \varphi A \chi=\mathrm{f}_{3}\left[\pi_{i}+\left(1 \mathrm{i} \pi_{i}\right) \varphi\right] \mathrm{i} \pi_{i}(1 \mathrm{i} p)(1 \mathrm{i} \varphi) \mathrm{g} A \chi \mathbf{i} r, \\
& w_{i}^{h}=1 \mathbf{i} \theta_{i}^{h} \quad A \chi=1 \text { i } \theta_{i}^{l} \varphi A \chi+(1 \text { i } p)(1 ; \quad \varphi) A \chi \text {. }
\end{aligned}
$$

The wedge between state-contingent earnings, i.e. the price for the temptation to misre port, is decreasing in investor protection. If the cost of hiding pro..ts is high, temptation to misreport is low, as is its price in terms of distance from the ..rst best. The ratio between payous and ability is lower than in the ec cient case, and increasing in $p$. This means that, by discouraging misbehavior, investor protection also fosters meritocracy. Expected earnings for entrepreneurs are the same as under perfect investor protection, but expected utility is lower, due to risk aversion. Notice that for $p=0$, the optimal ..nancial contract implies state independent repayments, which leave the entire risk on the entrepreneur.

Technological choice

The solution to $(P 2)$ features a threshold ability level $\pi^{\text {x }}$ such that the Risky technology is chosen by any agent with ability higher than $\pi^{\alpha}$. This property is formalized in Lemma 1.

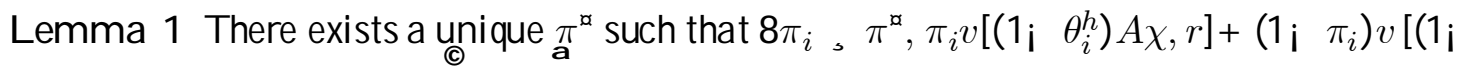
$\left.\left.\theta_{i}^{l}\right) \varphi A \chi, r\right], B \chi \mathbf{i} r$, and ${ }_{\theta_{i}^{h}, \theta_{i}^{l}}^{l^{2}}$ is the solution to $(P 1)$.

Proof. See the A ppendix.

\subsubsection{Investor protection and the equilibrium}

Since the dividend payouts ${\stackrel{C}{\theta_{i}}}_{i}^{h}, \theta_{i}^{l}$ a are functions of investor protection, also the threshold ability $\pi^{\text {}}$ varies with $p$, as formalized in Lemma 2

Lemma 2 The threshold ability $\pi^{\ltimes}$ is a decreasing, convex function of investor protection $p$.

Proof. See the A ppendix.

Notice that the risky technology is chosen only when some degree of risk sharing is attainable through the ..nancial contract. Thus, the measure of agents who become risky 
entrepreneurs represents the size of the market for risk sharing. Safe ..rms instead get started and operated regardless of the borrowing conditions in the ..nancial market. From Lemmas 1 and 2, it follows that the size of the market for risk sharing is a function of investor protection, as stated by Proposition 1.

Proposition 1 The size of the market for risk sharing, $M^{\prime} 1_{\mathrm{i}} G\left(\pi^{\ltimes}\right)$, is increasing in investor protection, and concave for high $p$.

Proof. See the A ppendix.

Corollary 1 De.ne the size of the overall external ..nance as $F^{\prime} K_{Y}+1$. The size of the market for risk sharing as a ratio of the total external ..nance, $\frac{M}{F}$ is increasing in investor protection and concave for high $p$.

Proof. See the A ppendix.

In the el cient case $(p=1)$, the value of producing with the risky technology is higher than that of running the safe project whenever $\left[\pi_{i}+\left(\begin{array}{ll}1 & \pi_{i}\end{array}\right) \varphi\right] A, B$. Therefore, I can easily get a closed form solution for the threshold ability,

$$
\pi_{p=1}^{\mathfrak{\alpha}}=\frac{B \mathrm{i} A \varphi}{(1 \mathrm{i} \varphi) A}
$$

and verify that it lies in the support of $\pi$ under the hypotheses that $A>B$ and $\varphi A<B$.

In the general case of imperfect investor protection $(p<1)$, the expression for the threshold ability is more complicated. However, payous are easily derived:

$$
\begin{aligned}
& 8 \\
& \text { ₹ } B \chi \mathbf{i} \quad r \text { with probability } 1 \text { for } \pi_{i}<\pi^{\text {ळ }} \\
& w\left(\pi_{i}\right)=\left\{\begin{array}{lll}
w_{i}^{h} & \text { with probability } \pi_{i} & \text { for } \pi_{i}, \pi^{\infty} \\
w_{i}^{l} & \text { with probability } 1 \mathbf{i} \pi_{i} & \text { for } \pi_{i}, \pi^{\infty}
\end{array}\right. \\
& w_{i}^{h}=\left[\pi_{i} p(1 \mathbf{i} \varphi)+\varphi+(1 ; p)(1 \mathbf{i} \varphi)\right] A \chi \mathbf{i} r \\
& w_{i}^{l}=\left[\pi_{i} p(1 \mathbf{i} \varphi)+\varphi\right] A \chi \mathbf{i} r .
\end{aligned}
$$

Henceforth, I denote the threshold abilities associated with $p=1$ and $0<p<1$ by $\pi_{p=1}^{\mathfrak{\alpha}}$ and $\pi_{p<1}^{\alpha}$, respectively. For $p=1$, perfect risk sharing is achieved through the optimal ..nancial contract, so that entrepreneurs act as if they were risk-neutral. They choose the risky technology as soon as their ability implies expected earnings equal to the safe ones, i.e. $\pi_{i}=\pi_{p=1}^{\ltimes}$. This means that their earnings are state invariant and exhibit no discontinuity at the threshold ability level. When $0<p<1$, at $\pi_{i}=\pi_{p<1}^{\mathrm{\alpha}}$ the expected productivity of the risky technology needs to be higher than the productivity of the safe technology, because entrepreneurs are risk averse and cannot be fully insured by investors. 


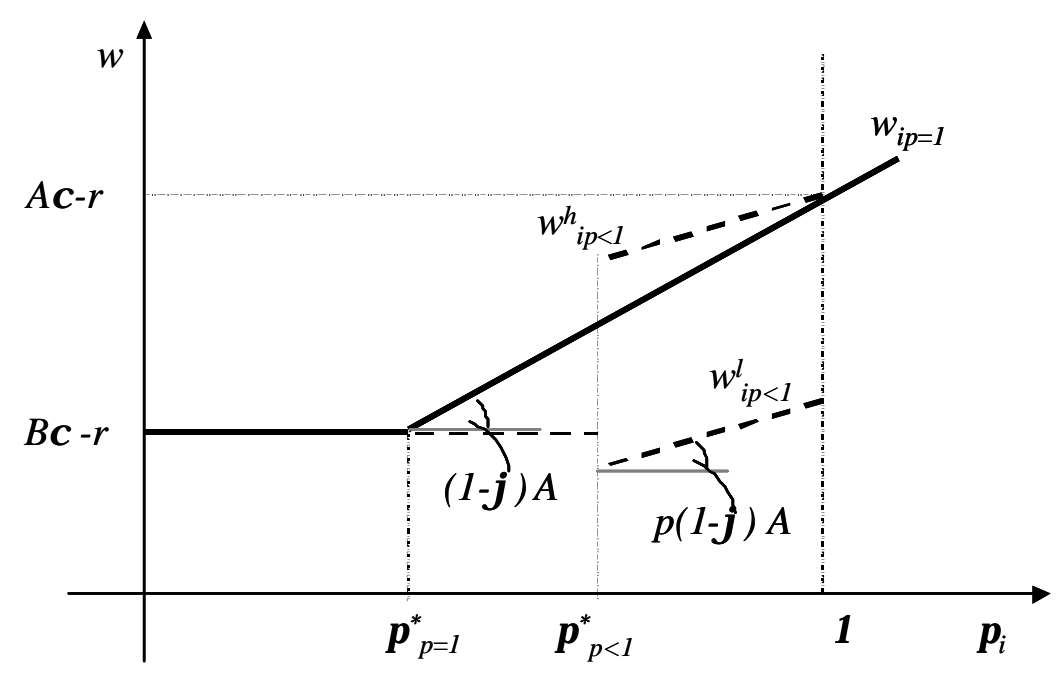

Figure 2: Model solution: ability-earnings pro..les.

F igure 2 illustrates the optimal ability-earnings pro..les. If there is no investor protection, nobody chooses the risky technology and hence earnings are $\neq$ at and equal to $B \chi-r$. In the opposite extreme case of $p=1$, income of young agents is described by the solid line. It is $\ddagger$ at for the less able, who run the safe project, and proportional to ability for the more talented, risky entrepreneurs. Due to perfect risk sharing, earnings are state invariant. If investor protection drops to $0<p<1$ (dashed line), ..nancing a risky ..rm becomes more costly, thereby inducing the least able among risky entrepreneurs to shift to the safe sector. G raphically, (1) the market for risk sharing shrinks, i.e., the fat portion of the earnings pro..le becomes longer. I de..ne this as the "market size" exect. (2) Proportionality between stochastic payoxs and ability becomes weaker due to higher incentives to misreport, and the wedge between state contingent earnings widens due to worse risk sharing. I call this, as illustrated by the fatter slope and higher distance between $w_{i p<1}^{h}$ and $w_{i p<1}^{l}$, the "insurance" exect. The extent of imperfect insurance is captured by the jump in expected earnings at $\pi_{p<1}^{\mathfrak{a}}$. At any $\pi_{i}, \pi_{p<1}^{\mathfrak{x}}$, the expected payo from the risky technology is independent of $p$ since, for a given interest rate, the old are indixerent be tween borrowers. However, even though expected earnings are invariant, welfare is higher under perfect investor protection because of risk aversion. 


\section{Eval uat ing income inequal it y}

In this section, I derive the key implications of the model on the overall exect of investor protection on income inequality, through the development of the market for risk sharing. To do so, I compute the variance of earnings,

$$
\begin{aligned}
& \operatorname{Var}(w)=G\left(\pi^{\ltimes}\right)[B \chi \mathbf{i} r \mathbf{i} E(w)]^{2}+{ }_{1}^{\mathbf{Z}_{1 / 2}} \mathbf{h} w^{h}(\pi) \mathbf{i}_{E(w)} \mathbf{i}_{2} \\
& +(1 ; \quad \pi)^{\mathrm{h}} w^{l}(\pi) \mathbf{i} E(w)^{\mathbf{i}_{2}^{3 / 4^{4^{2}}}} g(\pi) d \pi
\end{aligned}
$$

with $E(w)=G\left(\pi^{\ltimes}\right) B \chi+A \chi{ }_{\pi^{\natural}}^{\mathrm{R}_{1}}\left[\pi+\left(1_{\mathbf{i}} \pi\right) \varphi\right] g(\pi) d \pi \mathbf{i} \quad r$, and study how it varies with $p .^{11}$

If there is no investor protection, all agents choose the safe technology and thus, the variance is zero. If the cost of hiding cash $¥$ ow becomes any higher than zero $(p=\varepsilon)$, some agents prefer the risky technology and get insured while raising funds, thereby driving the size of the market for risk sharing from zero to $M(\varepsilon)$. By the "market size" exect, a share of the economy becomes subject to income risk (having state-contingent earnings), thereby raising the variance of income (analytically, positive terms fall under the integral). Moreover, average earnings grow higher than $B \chi$, so that also the agents on the $\ddagger$ at portion in Figure 2 contribute to raising the variance.

As investor protection improves, the "market size" exect is paired with the "insurance" exect, that shrinks the wedge between state-contingent earnings and hence, tends to reduce the variance. A nalytically, the "insurance" exect tends to reduce the term under integration. The extent of the "market size" exect is decreasing in investor protection, due to the concavity of $\mathrm{M}$ at high $p$. On the other hand, "insurance" becomes more exective, the larger is the mass of agents that bene..t from it. This means that, when investor protection is weak ( $M$ is small), the market-size exect dominates because risk sharing applies to a small fraction of the economy. Therefore, inequality at ..rst increases with $p$ (and with $M$ ).

When investor protection is perfect, $\operatorname{Var}(w)=G^{\mathrm{i}} \pi_{p=1}^{\mathrm{\alpha}}{ }^{\Phi}[B \chi \mathbf{i} \quad r \mathbf{i} E(w)]^{2}+{ }_{\pi_{p=1}^{\natural}}^{\mathrm{R}_{1}} \mathrm{f}[\pi+$ $\left.\left(\begin{array}{ll}1_{\mathbf{i}} & \pi\end{array}\right) \varphi\right] A \chi \mathbf{i} \quad r \mathbf{i} E(w) g^{2} g(\pi) d \pi>0$. As $p$ falls any lower than $1\left(p=1_{\mathbf{i}} \quad \varepsilon\right)$, the "market size" exect drives only few agents out of the risky sector, thereby reducing income inequality by a small amount, since the dixerence between $\mathrm{B} \chi, \mathrm{w}^{h}\left(\pi^{\mathrm{\alpha}}\right)$ and $\mathrm{w}^{l}\left(\pi^{\mathrm{\alpha}}\right)$ is still slight. The "insurance" exect, instead, applies to a large share of the population, and outweighs the "market size" exect, so that there is an increase in income inequality.

\footnotetext{
${ }^{11}$ Since income of the old is 1-to-1+r linked to that of the young, I focus on the earnings of the active population only.
} 
Therefore, improvements upon an already very good investor protection may in fact re duce inequality, although never below the case of no investor protection. Lemma 3 and Proposition 2 formalize this intuition.

Lemma 3 The variance of earnings is a non-monotonic function of investor protection: $\frac{d \operatorname{Var}(w)}{d p}>0$ in a neighbor hood of $p=0$, and $\frac{d \operatorname{Var}(w)}{d p}<0$ in a neighborhood of $p=1$.

Proof. See the A ppendix.

Since, from Proposition 1, the size of the market for risk sharing $(M)$ is continuous and monotonic in investor protection $(p)$, also the relationship between the former and income inequal ity follows a non-monotonic pattern.

Proposition 2 The relationship between earnings variance and the size of the market for risk sharing, $M^{\prime} 1$ i $G\left(\pi^{\ltimes}\right)$, is non-monotonic: $\frac{d \operatorname{Var}(w)}{d M}>0$ in a neighborhood of $\mathrm{M}(0)$, and $\frac{d \operatorname{Var}(w)}{d M}<0$ in a neighborhood of $\mathrm{M}(1)$.

Proof. See the A ppendix.

Proposition 2 shows that income inequality, as measured by the variance of earnings, increases with the size of the risk-sharing market for small $M$ and falls with large $M$. However, this does not give a full characterization of the relationship between inequality and the size of the risk-sharing market for any $p$. Moreover, there are alternative measures of inequality, such as the Gini coec cient, that are more commonly used in empirical work. Since a characterization of this indicator is awkward to derive analytically, I obtain it through numerical solution. This exercise allows me to study the relationship between investor protection, the size of the risk-sharing market and income inequality on the whole domain of $p$ and to obtain a more testable version of the prediction in Proposition $2{ }^{12}$

To simulate the model, I choose parameter values consistently with the restrictions imposed on parameters throughout the paper. ${ }^{13}$ I approximate the distribution of ability with a Lognormal $(\mu, \sigma)$ and parametrize the mean and variance of the associated Normal distribution, $\mu$ and $\sigma$, with values from the actual data. Although ability per se is diф cult to measure, it is likely to be refected in educational attainment. Therefore, I take the sample mean and variance of school years from the Barro and Lee (2000) database of 138 countries in 1995. Since the support of the Lognormal distribution is unbounded from

\footnotetext{
${ }^{12}$ If the assumption that risky output in the bad state is lower than the international interest rate is removed, some of the most able agents can ..nance the risky project, even at $p=0$. This means that the upper bound for the threshold ability becomes $\pi<1$ s.t. $\pi v(A \mathbf{i} \quad r)+\left(1_{\mathbf{i}} \pi\right) v\left(\varphi A_{\mathbf{i}} \quad r\right)=v(B \mathbf{i} r)$, and the size of the risk-sharing market is $G(\pi)$ i $G\left(\pi^{\alpha}\right)$. All results hold, after this relab eling.

${ }^{13} \mathrm{~N}$ otice that this numerical solution is for qualitative rather than quantitative purposes. Therefore, the technological parameters are not calibrated to the actual data.
} 

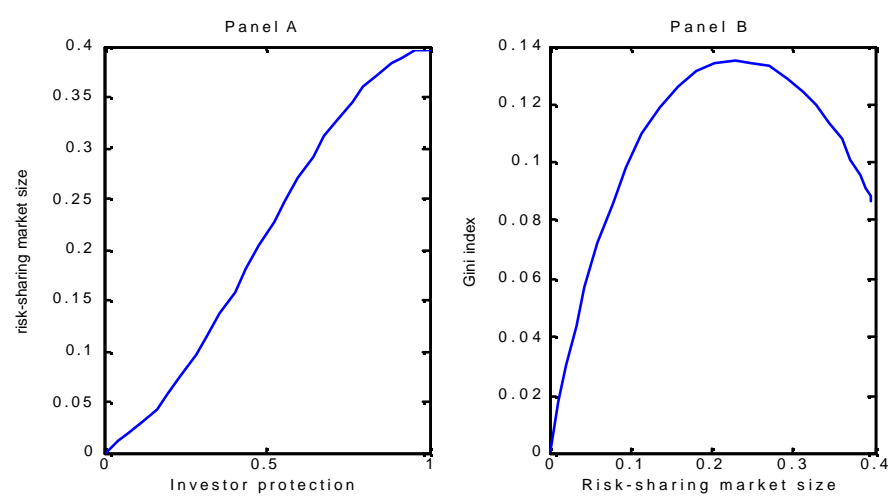

Figure 3: Investor protection, Risk-sharing market size and income inequality. Simulation output.

above, it must be truncated to comply with the set-up of the model. I assume the top 0.05 per cent to have ability 1 , while $\pi$ is lognormally distributed across the remaining 99.95 per cent of the population. I parameterize $\mu$ and $\sigma$ to match the US data, where the average years of schooling are 14.258, with a variance of 26.93. I normalize the resulting ability distribution so that it ..ts in the interval $[0,1]$, consistent with the model. I set $\alpha=$ 0.33, $\chi=1.5, r=0.06, B=1, A=2.84, \varphi=0.014$, implying $M(p=1)$ ' 0.4 .

Both the "market size" and the "insurance" exects are expected to arect the Gini coec cients and the variance of earnings in similar ways. Panel A of Figure 3, plotting the $G$ ini coec cient against the size of the risk-sharing market, con..rms the expectations: the Gini exhibits a non-monotonic pattern, featuring a hump with its peak at a high $M$. Panel B shows market size to be a function of investor protection, with the properties predicted by Proposition 1.

\section{E mpir ical evidence}

The model developed through sections 2 and 3 generates two main predictions: (1) Income inequality has a hump-shaped relationship with the size of the market for risk sharing, and (2) this market is bigger, the better is investor protection. Here, I empirically assess these results by applying a series of cross-section and panel data methodologies. The section is structured as follows: I ...st present the data, then the econometric techniques, and ..nally report and comment on the results. 
I use a cross-section of 68 countries observed between 1980 and 2000, and a panel of 50 countries with 144 non-overlapping ...ve-year observations spanning from 1976 to $2000 .{ }^{14}$

As a measure of income inequality, I take the Gini coet cient of the net individual income distribution from Dollar and K raay's (2002) database, which relies on four sources: the UN-WIDER World Income Inequality Database, the "high quality" sample from Deininger and Squire (1996), Chen and R avallion (2001), and Lundberg and Squire (2000). ${ }^{15}$

I proxy the size of the market for risk sharing with data on the ..nancial structure of countries. It can be argued that entrepreneurs bear more risk the larger their ..rm's leverage. In terms of standard ..nancial contracts, this means that ..rms' insiders achieve more (less) risk sharing in countries where equity (debt) accounts for a larger share of external ..nance. Therefore, I use stock market capitalization as a share of total credit to the private sector as empirical counterpart for the size of the risk-sharing market. This variable (smpr) is constructed as the ratio between stock market capitalization over GDP (smcap) and credit to the private sector over GDP (privo), from the database by Beck et al. (2001) on Financial Development and Structure, which expands the data used in Beck et al. (1999).

The indicators of investor protection and et ciency of the judiciary come from LLS (2006). Both investor_pr and $e f f_{-} j u d$ are indexes scaling from 0 to 10 in ascending order of protection and ec ciency. See LLS (2006) for a detailed description.

When estimating equations for the Gini's as a function of stock market capitalization over total credit, I control for a number of other relevant variables, as suggested by the model and by the empirical literature on inequality. In particular, I include real per capita GDP and its square to account for technology dixerences and the K uznets hypothesis. I also control for government expenditure and trade as a share of GDP. These variables are taken from Heston and Summers' version 6.1 of the Penn World Tables. ${ }^{16}$ I take two

\footnotetext{
${ }^{14} \mathrm{~T}$ he cross-section shrinks to 42 observations when I account for investor protection and ec ciency of the judiciary in the regressions, since these variables are only available for 49 countries, some of which do not intersect with the wider dataset. I use the full panel dataset only for the static regressions. Since 18 countries have less than the three consecutive observations needed for the A rellano and B over (1995) estimation, I perform the dynamic panel GMM on a restricted sample of 112 observations for 32 countries.

${ }^{15} \mathrm{~T}$ he original sample consists of 953 observations, which reduce to 418 separated by at least ...ve years, on 137 countries over the period 1950-1999. Countries dixer with respect to the survey coverage (national vs subnational), the welfare measure (income vs expenditure), the measure of income (net vs gross) and the unit of observation (households vs individuals). Data from Deininger and Squire are usually adjusted by adding 6.6 to the $\mathrm{G}$ ini coec cients based on expenditure. Here, the adjustment was made in a slightly more complicated way to account for the variety of sources; see Dollar and Kraay (2002) for details.

${ }^{16}$ T hroughout the estimations, real per capita GDP is expressed as a ratio of the ..rst observation for the US (1980 in the cross-section, 1976 in the panel).
} 
measures of education attainment to proxy both the level and the dispersion of human capital. I use the share of the population aged above 25 with some secondary education ( $\sec 25$ ), from the B arro and Lee's (2000) database, and the Gini coet cient for the years of education in the population aged above 15 ( $g h_{-}$15), constructed by Castellò and Doménech (2002) with data from Barro and Lee (2000).

F inally, as in LLS (2006), I use legal origins, from the World Development I ndicators, as instruments in the cross-sectional analysis.

\subsection{E st imation st $r$ at egies}

\subsubsection{Cross-section}

To test the predictions of the model across countries, I estimate the following static equation:

$$
G_{i\left(t_{\mathrm{i}} k, t\right)}=\alpha+\beta \mathbf{X}_{i\left(t_{\mathrm{i} k, t)}\right.}+\gamma_{1} \operatorname{smpr}_{i\left(t_{\mathrm{i}} k, t\right)}+\gamma_{2}{ }^{\mathrm{i}} R S_{i\left(t_{\mathrm{i}} k, t\right)}{ }^{\$}+\epsilon_{i},
$$

where $G_{i\left(t_{i} k, t\right)}$ is the Gini coec cient, the terms in $\mathbf{X}_{i\left(t_{\mathrm{i}} k, t\right)}$ are additional explanatory variables, and $\operatorname{smpr}_{i\left(t_{i} k, t\right)}$ is stock market capitalization as a ratio of total credit to the private sector. Subscripts $i(t \mathbf{i} k)$ indicate the average of a variable observed in country $i$ in the period between $t_{\mathbf{i}} k$ and $t$, that means 1980 and 2000 in the case of cross-sectional regressions. $\mathbf{X}_{i(t ; k, t)}$ includes: real per capita GDP observed at time $t \mathbf{i} k$ and its square; period averages of the share of population aged above 25 , with some secondary education ( $\sec 25$ ), and alternatively of the $G$ ini coec cient of the years of education in the population aged above 15 ( $g h_{-}$15); the period averages of government expenditure and trade as ratios of GDP. For sensitivity analysis, I replace $G_{i(t ; k, t)}$ with $G_{i t}$. The main result of the model is con..rmed by the data if $\hat{\gamma}_{1}>0$ and $\hat{\gamma}_{2}<0$.

The OLS estimates of $\gamma_{1}$ and $\gamma_{2}$ may be biased if there is reverse causation betwen income inequality and stock market size. To control for this possibility, I also estimate equation (4) by T wo-Stages $L$ east Squares, using a number of investor protection indicators as instruments for $\operatorname{smpr}_{i(t ; k, t)}$ :

$$
\begin{aligned}
& G_{i\left(t_{\mathbf{i}} k, t\right)}=\alpha+\beta \mathbf{X}_{i\left(t_{\mathrm{i}} k, t\right)}+\gamma_{1} s m p r_{i\left(t_{\mathrm{i} k, t)}\right.}+\gamma_{2}{ }^{\mathbf{i}} \operatorname{smpr}_{i\left(t_{\mathrm{i}} k, t\right)}{ }^{\boldsymbol{\phi}_{2}}+e_{i} \\
& \operatorname{smpr}_{i\left(t_{\mathrm{i}} k, t\right)}=\zeta+\xi \mid \mathbf{P}_{i\left(t_{\mathrm{i}} k, t\right)}+u_{i} \text {. }
\end{aligned}
$$

This strategy also allows me to evaluate the intermediate link between investor protection and the size of the risk-sharing market. I adopt two alternative sets of instruments, $I \mathrm{P}_{i\left(t_{\mathrm{i}} k, t\right)}$, for stock market capitalization over total credit: (i) the indicators of investor 
protection and eq ciency of the judiciary suggested by LLS (2006) as determinants of stock market development; (ii) the origin of the legal system which is, in turn, used by LLS (2006) to instrument investor protection. The main advantage of the second set of instruments is that these are most certainly exogenous and available for a wider crosssection of countries. The IV estimation validates the theoretical prediction on the positive relationship between investor protection and risk sharing, if $\hat{\xi}>0$ and the $F$ statistics of the excluded instruments from the ..rst-stage regression is high. If the Sargan test of overidentifying restrictions has a high $\mathrm{p}$-value, excluding correlation between investor protection and the residuals $e_{i}$, the data suggest that the whole mechanism suggested by the model is plausible: investor protection axects income inequality precisely through its eaect on the risk-sharing market.

\subsubsection{Fixed and random exects}

To test the results of the paper both across countries and over time, I use the panel data methodology and estimate the following equation:

$$
G_{i t}=\alpha+\beta \mathbf{X}_{i t}+\gamma_{1} \operatorname{smpr}_{i t}+\gamma_{2}\left(\operatorname{smpr}_{i t}\right)^{2}+\eta_{i}+\nu_{t}+\epsilon_{i t},
$$

where $G_{i t}$ is the average Gini coec cient observed in country $i$ over a ..veyear period $t$, the terms in $\mathrm{X}_{i t}$ and $s m p r_{i t}$ are the same as for equation (4), and $\eta_{t}, \nu_{t}$ and $\epsilon_{i t}$ are unobservable country- and time-speci..c exects, and the error term, respectively. I estimate equation (5) under the alternative hypotheses of a random versus ..xed idiosyncratic component $\eta_{i}$. Fixed-exects estimates capture the evolution of the relationship within each country over time. Random exects are more ec cient, since they exploit all the information available across countries and over time. However, the latter may be inconsistent if country-speci..c exects are correlated with the residuals. Including time ..xed exects in both regressions allows me to account for the presence of global trends, such as skill-biased technical change, which drives inequality worldwide. I rely on the Hausman test for the choice between FE and $R E$, and an $F$ test for the inclusion of time dummies.

\subsubsection{Dynamic Panel Data}

As a further evaluation of the rel ationship between risk-sharing market size and inequality, I follow the latest approach of dynamic panel analysis, and focus on the expression:

$$
g_{i t}=\lambda g_{i \mathrm{i} \mathbf{1} 1}+\beta^{0} \mathbf{x}_{i t}+\tau_{1} s m p r_{i t}+\tau_{2}\left(s m p r_{i t}\right)^{2}+\eta_{i}+\nu_{t}+\epsilon_{i t},
$$


where all variables are expressed in logarithms. Notice that the speci..cation in equation (6) includes a lagged endogenous variable among the regressors. It immediately follows

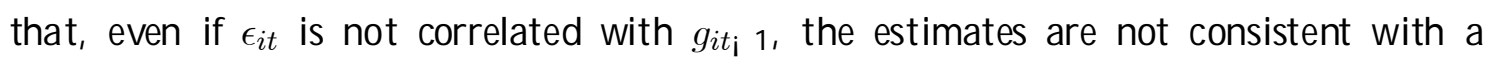
..nite time span. Moreover, consistency may be undermined by the endogeneity of other explanatory variables, such as income and stock market capitalization. A number of contributions provide theoretical support (see, for instance, Banerjee and Duキ0, 2003, Barro, 2000, Benabou, 1997, Forbes, 2003, and Lopez, 2003) and empirical treatments for the simultaneity between growth and inequality. Feed backs with stock market size instead capture the reaction of capital supply to changes in the income distribution. To correct for the bias created by lagged endogenous variables and the simultaneity of some regressors, I adopt the approach of Arellano and Bover (1995) and Blundell and B ond (1998). ${ }^{17}$ I time-digerentiate both sides of (6) to obtain

$$
\pitchfork g_{i t}=\lambda \pitchfork g_{i t_{\mathrm{i}} 1}+\beta^{0} \phi \mathbf{x}_{i t}+\tau_{1} \phi s m p r_{i t}+\gamma_{2} \phi\left(s m p r_{i t}\right)^{2}+\phi \nu_{t}+\phi \epsilon_{i t},
$$

and estimate the system of equations (6) and (7). The dixerences in the variables that are either endogenous or predetermined can be instrumented with their own lagged values, while lagged dixerences are instruments for levels. For instance, I use $g_{i t ;} 3$ as an instrument for $\phi g_{i i_{\mathrm{i}} 1}$ and $s m p r_{i t_{\mathrm{i}} 2}$ for $\phi s m p r_{i t}$, as well as $\phi g_{i t_{\mathrm{i}}} 2$ and $\phi s m p r_{i t_{\mathrm{i}} 1}$ for $g_{i t ;} 1$ and $s_{m p r}$. The estimation is performed with a two-step System-GMM technique. The moment conditions for the equation in dixerences are $E\left[\phi g_{i t ; s}\left(\epsilon_{i t} \mathbf{i} \epsilon_{i t ; 1}\right)\right]=0$ for $s, 2$, and - if the explanatory variables $y$ are predetermined $-E\left[\$ y_{i t_{\mathrm{i}} s}\left(\epsilon_{i t} \mathbf{i} \epsilon_{i t \mathrm{i}}{ }_{1}\right)\right]=0$ for $s, 2$. For equation (6), the additional conditions are $E\left[\phi g_{i, t_{\mathrm{i}} s}\left(\eta_{i}+\varepsilon_{i, t}\right)\right]=0$ and $E\left[\varnothing y_{i, t_{\mathrm{i}} s}\left(\eta_{i}+\varepsilon_{i, t}\right)\right]=0$ for $s=1$. The validity of the instruments is guaranteed under the hypothesis that $\epsilon_{i t}$ exhibit zero second-order serial correlation. Coet cient estimates are consistent and ec cient, if both the moment conditions and the no-serial correlation are satis..ed. I can validate the estimated model through a Sargan test of overidentifying restrictions, and a test of second-order serial correlation of the residuals, respectively. As pointed out by Arellano and Bond (1991), the estimates from the ..rst step are more ef..cient, while the test statistics from the second step are more robust. Therefore, I will report coec cients and statistics from the ..rst and second step, respectively.

\footnotetext{
${ }^{17}$ T he system-D PD methodology dominates the dixerence-DPD proposed by A rellano and B ond (1991), because it amends problems of measurement error bias and weak instruments, arising from the persistence of the regressors (as pointed out by Bond et al., 2001).
} 


\subsection{R esults}

\subsubsection{Cross-sectional regressions}

Table 1 reports the $O$ rdinary Least Squares estimates for dixerent versions of equation (4). Columns 1-7 suggest human capital and stock market development to be the major forces driving income inequality. As predicted by the model, $\hat{\gamma}_{1}$ is positive and signi..cant for both measures of stock market development, while $\hat{\gamma}_{2}$ is negative. According to the estimates, an increase in the relative size of the stock market should start reducing inequality after smpr has crossed a level that only three countries have reached in the sample. The fact that only very few countries are beyond the point where the relationship between risk sharing and inequality becomes negative may explain the low statistical signi..cance for $\hat{\gamma}_{2}$. Moreover, the model predicts that inequality should never completely revert, even when the stock market achieves its maximum relative size; hence, it is reasonable to expect the linear term to be generally more signi..cant, as is the case in Table 1.

In column 3, I control separately for stock market size and a measure of overall ..nancial development, the ratio of credit to the private sector over GDP (privo). Interestingly, the coec cient estimates suggest that equity-like and debt-like..nance have opposite exects on income inequality (positive and negative, respectively), as predicted by the model. The negative coec cient for privo is in line with the evidence by B eck et al. (2006) and Clarke et al. (2006), while the positive coec cient for smpr is novel in the literature.

The signi..cant, negative coec cients on sec 25 through columns 1-3 and 6, in line with most empirical evidence, mean that inequality tends to be lower, the larger is the share of the population with high education. The positive and signi..cant estimates for $g h \_15$ in columns 4-5 show that the dispersion of human capital boosts income inequality. However, the coec cients for sec 25 and $g h_{-} 15$ jointly estimated (column 6) suggest that the former is more signi..cant. Given that $\sec 25$ dominates $g h_{-} 15$, I will henceforth report the results obtained with $\sec 25$ only. Finally, for the Kuznets hypothesis to hold, the estimated coet cients of $G D P$ and $(G D P)^{2}$ should be positive and negative, respectively. The results in Table 1 do not allow me to validate this hypothesis, due to the lack of signi..cance of both coeф cients.

To get a quantitative $\neq$ avor of the implications of column 2 and 3, take pairs of countries with similar human capital (theother main determinant of in equality) but dixerent relative size of the stock market, and compare the actual Gini dixerentials with their predicted values. Venezuela and South A frica, for instance, had very similar school attainment ( 29.3 and 28.5 per cent of the population aged above 25 with secondary education), while stock market capitalization over GDP was eleven times larger in South A frica. Column 3 would 
predict a lower Gini coeł cient in Venezuela, with a dixerence of about 19 points: very close to the actual 18. Consider also A ustria, which had the same level of secondary school attainment as Switzerland (65.1 vs 65.3), but a much less developed stock market ( $\mathrm{smpr}$ was seven times smaller). Its predicted Gini (from the estimates in column 2) is lower than the Swiss by 6.8 vs the actual 7.1 points. ${ }^{18}$

The results in Table 1 support the main prediction of the model on the relationship between size of the risk-sharing market and income inequality, but cannot provide evidence on the mechanism generating it, starting from investor protection. To see if investor protection axects income inequality independently from the risk-sharing market, I ..rst regress the Gini coed cient on the control variables in X and LLS's indicator of investor protection, and then add smpr. Table 2 shows that investor_pr has indeed a positive and signi..cant exect on income inequality. However, the coeł cients in columns 2 and 3 suggest that this exect is absorbed by stock market capitalization over total credit, once I control for it. Moreover, column 3 support the hypothesis that investor protection has no exect on inequality, unless paired by a bigger relative size of the stock market. These results suggest that investor protection only axects income inequality through the development of the equity market relative to debt.

The instrumental variables estimates reported in Table 3 are meant to explicitly account for the intermediate step linking risk sharing to the degree of investor protection. Estimating the ..rst step of the IV regressions allows me to partially replicate the analysis in LLS (2006) to verify the predictive power of investor protection and ed ciency of the judiciary on the size of the market for risk sharing. The coet cients from the ..rst step estimations in column 3 of Panel A con..rm that better investor protection and ed ciency of the judiciary system boost the development of the market for risk sharing. Since these variables could be endogenous, I replace them with legal origins when estimating the ..rst step for smpr. Columns 1-2 con..rm the results in LLS (2006) that the common law (UK) legal origin strongly promoted the development of stock markets.

Panel B of Table 3 reports the coed cient estimated in the second step, instrumenting smpr with legal origins and investor protection. The estimates for the relative size of the stock market strongly support the prediction that $\gamma_{1}>0$. The p-values of the $F$ and Sargan tests guarantee that both sets of instruments are valid. In other words, investor protection is a good predictor for smpr (result 1), and only axects inequality through stock market development. Estimating equation (4) instrumenting both the linear and the quadratic terms for smpr is problematic, given the collinearity of the instruments.

\footnotetext{
${ }^{18} \mathrm{R}$ emember that the $\mathrm{G}$ ini coec cient can, in principle, take values between zero and one hundred, and ranges between 22.6 and 58.3 in the sample.
} 
Therefore, I try to capture the non linearity in the exect of stock market development on income inequality by re-estimating the equations of column 1 on a restricted sample, excluding the countries with bigger stock markets (those with $s m p r>1.5$ ). The coec cient $\gamma_{1}$, reported in column 2 of $P$ anel $B$, is higher than the one in column 1 . This suggests that the relationship between the relative size of the stock market and the Gini's tend to revert when the market for risk sharing is big enough.

So far, I have regressed the average of the Gini coec cients between 1980 and 2000 on the average relative size of the stock market in the same period. To verify if the results are sensitive to the timing of observations, I replicate the regressions of Tables 1 and 3 in two alternative ways. First, I replace the average Gini with its latest available observation, after 1985, and keep the regressors as in the previous estimates. The results are reported in columns 1-4 of Table 4 and do not display major dixerences from Table 1 and 3. As a further check, I focus on the period 1985-2000 and regress the average Gini on the initial values of smpr. In this case, I do not need to perform instrumental variables estimations, since reverse causality is arguably ruled out by the choice of the timing of observations. As shown in columns 5 and 6 of Table 4, the estimates for the linear term of stock market size remain positive and signi..cant, while those for its square lose signi..cance Overall, the evidence from the sensitivity analysis favors strongly the existence of a positive $\gamma_{1}$ and, to a weaker extent, of a negative $\gamma_{2}$.

Finally, the robustness of the results is tested in Table 5, which reports the estimates of equation (5) where government expenditure and trade (as a ratio of GDP) are added as additional regressors. There are no major changes from Tables 1 and 3, and the additional coeł cients are not signi.. cantly dixerent from zero.

\subsubsection{Panel regressions}

Columns 1 and 2 in Table 6 report the coec cients of equation (5) estimated with random and ..xed exects on a panel of 50 countries, with 5-year observations spanning between 1976 and 2000. ${ }^{19}$ T he estimates con..rm the existence of a positive $\gamma_{1}$, but do not provide strong support for $\gamma_{2}<0$. The estimates in column 3 are in line with the results from the cross-section on the opposite exects of equity-like vis-à-vis debt-like ..nance on income inequality. Education turns out to be negatively related to inequality throughout all estimations, consistently with most of the empirical literature. The Kuznets hypothesis is not validated by the results in Table 6 . In conclusion, the static panel analysis suggests

\footnotetext{
${ }^{19}$ For all equations I ran regressions with both ..xed and random ex ects, then I chose the best speci.. cation relying on the (reported) Hausman test and reported coec cient estimates only for that one. The other results are available upon request.
} 
that stock market development plays as important a role as education in shaping income distribution.

The regression in Table 6 exploit the variation of inequality and market size across countries and through time. It cannot, though, account for the existence of dynamic feedbacks between inequality and stock market development. To overcome these methodological limitations, I adopt the approach of Arellano and Bover (1995) and Blundell and Bond (1998), and estimate various versions of system (6)-(7).

Table 7 reports the coec cients estimated with the two-step system GM M à la A rellano and Bover (1995). T hese results support again the existence of a signi..cant positive linear relationship between the Gini's and the relative size of the stock market. The quadratic term is also signi..cant and exhibits the expected negative sign. The estimates in column 3 imply that stock market development has signi..cant exects on income inequality in the short run, while the dynamic analysis suggests that these exects persist also in long run, with coec cients $\gamma_{1}=.36$ and $\gamma_{2}=-.212$. The positive $\gamma_{1}$ remains signi..cant after the inclusion of time, as well as time-continent exects. ${ }^{20}$ All estimated coet cients for the lagged Gini's support the convergence hypothesis for income inequality, as in previous empirical work by Benabou (1996), Lopez (2003) and Ravallion (2002). As in the crosssectional and static panel regressions, the K uznets' hypothesis ..nds no support and the predictive power of human capital becomes weaker.

When shifting from the static to the dynamic panel regressions, the countries with less than three consecutive observations are dropped from the sample. To make the results from the two pane techniques comparable, I replicate the Fixed and R andom Exects estimates on the reduced sample and report the coec cients in columns 4-6 of Table 6. The coec cients for smpr and its square are positive and negative, respectively, and both signi..cantly dixerent from zero, as in the dynamic panel of Table7.

As a robustness check, I re-estimate the equations in Tables 6 and 7 with government expenditure and trade over GDP as additional regressors, and report the results in Table 8. Both static and dynamic regressions support the prediction of a positive $\gamma_{1}$ and negative $\gamma_{2}$. The estimates for government expenditure, which are non-signi..cantly dixerent from zero, refect the ambiguity of theoretical predictions and previous empirical evidence. Neither are the coeł cients for trade openness signi..cantly dixerent from zero.

\footnotetext{
${ }^{20}$ Results with time-continent ea ects are available upon request.
} 


\subsubsection{Summary}

The estimates reported in this section suggest that the development of the market for risk sharing, proxied by the size of the stock market relative to private credit, tends to raise income inequality. The declining part of the hump predicted by the model is supported in a less robust way by the data. This evidence can be reconciled with the model, since the Gini coec cient is not expected to revert completely, even at very high levels of market development. Dynamic panel estimates show that the relationship between stock market development and income inequality continues to hold in the long run. Results from the cross-sectional regressions con..rm the prediction that investor protection only axects income inequality through the development of the risk-sharing market.

\section{Conclusions}

This paper provides theoretical predictions and empirical support for a systematic re lationship betwen investor protection, risk sharing and income inequality. I develop an overlapping generation model with risk-averse agents, heterogeneous in their ability, where production can take place with a safe or a risky technology. In the presence of ..nancial frictions, arising from the non-observability of realizations and imperfect investor protection, I study the occupational and ..nancial choices for dixerent ability groups. Better investor protection promotes risk sharing between entrepreneurs and ..nanciers and axects income inequality in a number of ways. First, it provides insiders with better insurance, thereby reducing income volatility for a given mass of risky entrepreneurs. Second, it raises the share of agents that choose the risky technology and are thereby exposed to earning risk. Finally, since ability axects risky payous, better investor protection also increases the overall reward to ability. The ..rst exect tends to reduce in equality, while the other two boost it. The main result of the paper is that income dispersion increases at ..rst with the size of the market for risk sharing, and then declines. In the empirical section, I provide evidence consistent with the predictions of the model. 


\section{$\mathrm{R}$ ef er ences}

[1] A cemoglu, Daron and Simon J ohnson, 2003 "Unbundling institutions," J ournal of Political Economy, forthcoming.

[2] A cemoglu, Daron and Fabrizio Zilibotti, 1997 “Was P rometheus Unbound by Chance? Risk, Diversi..cation and Growth," J ournal of Political Economy 105, 709-751.

[3] A cemoglu, Daron and Fabrizio Zilibotti, 1999 "Information A ccumulation in Development," J ournal of Economic Growth 4, 5-38.

[4] Aghion, Philippe and Patrick Bolton, 1992 "A n incomplete contracts approach to ..nancial contracting," Review of Economic Studies 59, 473-494.

[5] Aghion, Philippe and Patrick Bolton, 1997 "A theory of trickle-down growth and development," Review of Economic Studies 64, 151-172

[6] Aghion, Philippe, Peter Howitt and David Mayer-Foulkes, 2005 "The Exects of Financial Development on Convergence: Theory and Evidence," Quarterly J ournal of E conomics, 120 (forthcoming).

[7] A rellano, Manuel and Stephen Bond,1991 "Some tests of speci..cation for panel data: M onte Carlo evidence and an application to employment equations," Review of Economic Studies 58, 277-297.

[8] B anerjee, Abhijit and Esther Du $\neq, 2003$ "Inequality and growth: what can the data say?," J ournal of E conomic Growth (forthcoming).

[9] B anerjee, Abhijit and A ndrew Newman, 1993 "Occupational Choice and the Process of Development," J ournal of Political Economy 101, 274-298.

[10] B arro, R obert and J ong-W ha Lee, 2000 "International data on educational attainment: updates and implications," Harvard University Center for International Development Working Paper No 2.

[11] B eck, Thorsten, Asli Demirgüç-K unt and Ross Levine, 2000 "A new database on ... nancial development and structure," World Bank Economic R eview, September 2000, 597-605.

[12] B eck, Thorsten, Asli Demirgüç-K unt and Ross Levine, 2006 "Finance, Inequality and The Poor," mimeo

[13] B eck, Thorsten and Ross Levine, 2002 "Stock Markets, Banks, and Growth: Panel Evidence", NBER Working Papers 9082. 
[14] B enabou, Roland, 1996 "Inequality and Growth," NBER Macroeconomics A nnual, B. Bernanke and J. Rotemberg, eds., 11-74.

[15] B ehrman, J ere, Nancy Birdsall and Miguel Szekeley, 2001 "Economic Policy Dixerentials in Latin America," Penn Institute for E conomic R esearch W P 01-048.

[16] B olton, Patrick and Xavier Freixas, 2000 "Equity, Bonds and Bank Debt: Capital Structure and F inancial Market Equilibrium Under Asymmetric Information," The J ournal of Political Economy 108, 324-351.

[17] Castellò, A mparo and Rafael Doménech, 2002 "Human Capital Inequality and Economic Growth: Some New Evidence," The Economic J ournal, 112, C187-200.

[18] Castro, Rui, Gian Luca Clementi and Glenn MacDonald, 2004 "I nvestor protection, O ptimal Incentives and E conomic Growth," Q uarterly J ournal of E conomics, 119(3), 1131-1175.

[19] Chakraborty, Shankha and Tridip Ray, 2001 "I nequality, industrialization and ..nancial structure," University of Oregon, Eugene, mimeo.

[20] Clarke, George, Lixin Colin Xu and Heng-fu Zou, 2006 "F inance and Income I nequality: What Do The Data Tell Us?," Southern Economic J ournal 72, 578-596

[21] Constantinides, George M. and Darrell Duф e, 1996 "Asset Pricing with Heterogeneous Consumers," The J ournal of Political Economy, 104(2), 219-240.

[22] Deininger, K laus and Lyn Squire, 1996 "A new dataset measuring income inequality," W or ld Bank Economic Review 10(3), 565-91.

[23] Demirgüç-Kunt, Asli and Ross Levine, 2001 "Financial Structure and Economic Growth: A Cross-Country Comparison of Banks, Markets, and Development," MIT Press, Cambridge, MA

[24] Diamond, Douglas, 1991 "M onitoring and reputation: the choice between bank loans and directly placed debt," J ournal of Political E conomy 99, 689-721.

[25] Dollar, David and Aart K raay, 2002 "Growth is good for the poor," J ournal of Economic Growth 7, 195-225.

[26] Fairlie, Robert and Alicia Robb, 2003 "Families, human capital, and small business: evidence from the Characteristics of Business Owners survey," Yale University Economic Growth Center Discussion Paper No. 871. 
[27] Gale, Douglas and Martin Hell wig, 1985 "Incentive compatible debt contracts: the oneperiod problem," Review of Economic Studies 52, 647-663.

[28] Galor, O ded and J oseph Zeira, 1993 "Income Distribution and M acroeconomics," Review of Economics Studies 60, 35-52.

[29] Greenwood, Jeremy and Bojan Jovanovic, 1990 "Financial Development, Growth, and the Distribution of Income," J ournal of Political Economy 98, 1076-1107.

[30] Hart, Oliver, 1995 "Firms, contracts and ..nancial structure," Clarendon L ectures in Economics, Oxford University Press.

[31] Heston, A lan, Robert Summers and Bettina Aten, 2002 "Penn World Tables version 6.1," Center for International Comparisons at the University of Pennsylvania.

[32] K ing, Robert and Ross Levine, 1993 "F inance and Growth: Schumpeter Might be Right." Quarterly J ournal of Economics 108.

[33] La Porta, R afael, Florencio F. Lopez-de-Silanes, Robert Vishny and Andrei Shleifer, 1997 “Legal Determinants of External Finance” J ournal of F inance 52, 1131-1150.

[34] L a Porta, R afael, Florencio F. Lopez-de-Silanes, R obert Vishny and Andrei Shleifer, 1998 "Law and Finance," J ournal of Political Economy 106, 1113-1155.

[35] L a Porta, R afael, Florencio F. Lopez-de-Silanes, R obert Vishny and Andrei Shleifer, 1999 "Corporate Ownership A round the World," J ournal of F inance 54, 471-517.

[36] La Porta, R afael, Florencio F. Lopez-de-Silanes, R obert Vishny and Andrei Shleifer, 2000 "Investor Protection and Corporate Governance," J ournal of Financial Economics 58, 3-27.

[37] La Porta, Rafael, Florencio F. Lopez-de-Silanes and Andrei Shleifer, 2006 "W hat Works in Securities Laws?," J ournal of Finance (forthcoming).

[38] L evine, R oss, 2002 “Bank-Based or Market-B ased Financial Systems: Which is Better?," NBER Working Papers 9138.

[39] L evine, R oss and Sara Zervos, 1998 "Stock Markets, Banks, and E conomic G rowth," A merican Economic Review 88, 537-558.

[40] Lopez, Humberto, 2003 "Pro growth, pro poor: is there a trade ox?," World Bank, mimeo. 
[41] L undberg, M attias and Lyn Squire, 2000 "T he simultaneous evolution of growth and inequality," World Bank, mimeo.

[42] Piketty, Thomas, 1997 "T he dynamics of the wealth distribution and the interest rate with credit rationing," Review of Economic Studies 64, 173-189.

[43] Rajan, Raghuram and Luigi Zingales, 1995 "Is T here an Optimal Capital Structure? Some Evidence from International Data," J ournal of Finance 50, 1421-1460.

[44] Rajan, Raghuram and Luigi Zingales, 1998 "Financial Dependence and Growth," A merican Economic Review 88, 559-586.

[45] Rajan, Raghuram and Luigi Zingales, 2003 "The Great Reversals: The Politics of Financial Development in the 20th Century," J ournal of Financial Economics 69, $5-50$.

[46] R avallion, M artin, 2001 "M easuring aggregate welfare in developing countries: how well do national accounts and surveys agree?," World Bank Policy Research Department Working Paper No. 2665.

[47] Ravallion, Martin and Shaohua Chen, 1997 "What Can New Survey Data Tell us about Recent Changes in Distribution and Poverty?," The World Bank Economic Review, 11, 357-382.

[48] R obbins, Donald, 1996 "HOS Hits Facts: Facts W in; Evidence on Trade and Wages in the Developing World," HIID Discussion Paper 557, Harvard University.

[49] Schiller, Bradley and Philip Crewson, 1997 "Entrepreneurial origins: a longitudinal inquiry," Economic Enquiry 35, 523-532.

[50] Shleifer, Andrei and Daniel Wolfenzon, 2002 "Investor protection and equity markets," J ournal of F inancial E conomics 66, 3-27.

[51] Spilimbergo, A ntonio, J uan Luis Londoño and Miguel Székely, 1999 “Income Distribution, Factor Endowments, and Trade O penness," J ournal of Development E conomics, 59, 77-101.

[52] Storesletten, K jetil, Christopher Telmer and A mir Yaron, 2006 "Asset Pricing with I diosyncratic Risk and O verlapping Generations," manuscript, University of O slo. 


\section{A Proofs}

\section{Lemma 1}

The assumptions that $A>B$ and $\varphi A<B$ together with continuity of $V_{i}$ in $\pi_{i}$ imply the existence of a unique point $\pi^{\alpha} 2(0,1)$ where $V^{\alpha}=B \chi \dot{j} r$. From this, it follows that for

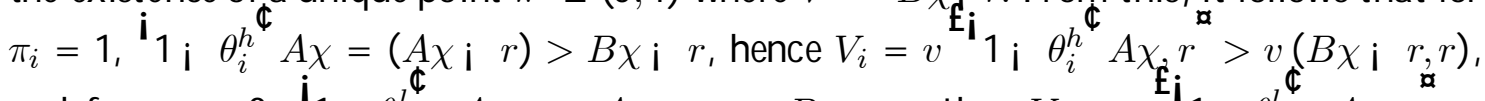

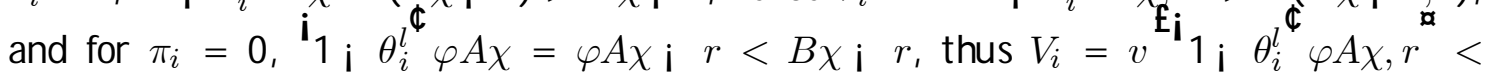
$v(B \chi \mathbf{i} r, r)$. To prove that $\pi^{\infty}$ is a threshold, I just need to show that $V_{i}$ is increasing in $\pi_{i}$. The derivative of $V_{i}$ w. r. t. $\pi_{i}$ under the optimal equity contract is

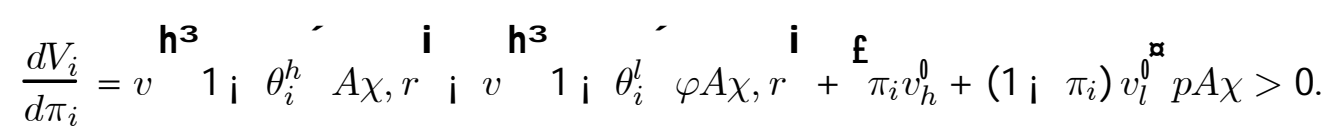

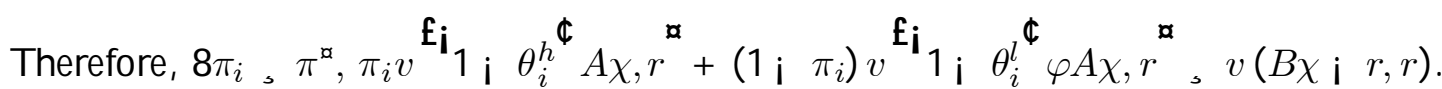

\section{Lemma 2}

To prove that the threshold ability is decreasing in investor protection, I obtain the derivative of $\pi^{\ltimes}$ with respect to $p$,

$$
\frac{d \pi^{\ltimes}}{d p}=i_{\frac{d V}{d p}}^{\mu} \frac{d V}{d \pi}^{\bigcap_{\mathrm{i} 1}}
$$

and show that it is negative. I have derived $\frac{d V}{d \pi^{\natural}}>0$ in the proof of Lemma 1. I just need to derive

$$
\frac{d V}{d p}=\pi_{i}\left(1 \mathbf{i} \pi_{i}\right)(1 \mathbf{i} \quad \varphi) A^{\mathrm{i}} v_{l}^{0} \mathbf{i} v_{h}^{0^{\$}} .
$$

Notice that $\frac{d V}{d p}>0$ for any $\pi$, since utility is concave. It follows that $\frac{d \pi^{\natural}}{d p}<0$.

To prove that the threshold is convex in investor protection, I need to prove that $\frac{d^{2} \pi^{\natural}}{(d p)^{2}}>0$.

$$
\begin{aligned}
& \frac{d^{2} \pi^{\ltimes}}{(d p)^{2}}=\frac{\frac{d^{2} V}{d \pi d p} \frac{d V}{d p} \text { i } \frac{d^{2} V}{(d p)^{2}} \frac{d V}{d \pi}}{\mathrm{I}_{\frac{d V}{d \pi}} \mathrm{L}^{2}}
\end{aligned}
$$

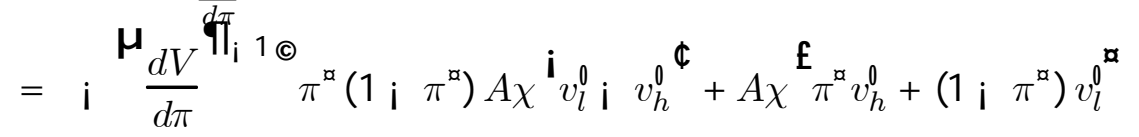

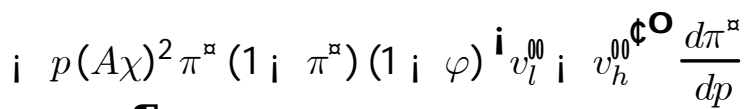

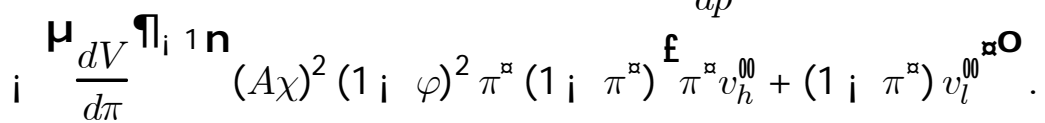

All terms divided by $\frac{d V}{d \pi}$ are positive, since the CRRA speci..cation of the utility function implies that $v_{l}^{0}>v_{h}^{0}$ and $v_{l}^{\boxplus}<v_{h}^{\infty}$, and $\frac{d \pi^{\natural}}{d p} \cdot 0$. Therefore, $\frac{d^{2} \pi^{\circledR}}{(d p)^{2}}=\mathrm{i}(>0)^{\mathrm{i}}{ }^{1} \mathrm{f}(, 0)+$ 
$(>0)$ i $\quad(\cdot 0) \mathrm{g}(\cdot 0) \mathrm{i} \quad(>0)^{\mathrm{i}}{ }^{1} \mathrm{f}<0 \mathrm{~g}>0$.

Proposition 1

To prove the increasing monotonicity of the size of the risk-sharing market, and its concavity at high levels of investor protection, I derive

$$
\begin{aligned}
& \frac{d M}{d p}=\mathrm{i} g\left(\pi^{\mathrm{\alpha}}\right) \frac{d \pi^{\mathrm{\alpha}}}{d p}
\end{aligned}
$$

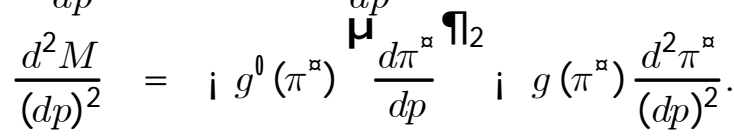

From L emma 1, $\frac{d \pi^{\alpha}}{d p} \cdot 0$, that implies $\frac{d M}{d p}, 0$; hence, the size of the market for risk sharing is increasing in investor protection. From Lemma 2, $\frac{d^{2} \pi^{\alpha}}{(d p)^{2}}>0$. Moreover, $\lim _{p !} \frac{d \pi^{\alpha}}{d p}=$ $\lim _{p ! 1} \frac{d V}{d p} \frac{d V}{d \pi}=\lim _{p !} \frac{\pi\left(1_{\mathbf{i}} \pi\right)\left(1_{\mathbf{i}} \varphi\right)\left[v^{0}\left(w^{l}, r\right) \mathbf{i} v\left(w^{h}, r\right)\right]}{\left(w^{h}, r\right) \mathbf{i} v\left(w^{l}, r\right)+\left[\pi v^{0}\left(w^{h}, r\right)+\left(1_{\mathbf{i}} \pi\right) v^{0}\left(w^{l}, r\right)\right] p A}=0$. It follows that $M$ is concave in $p$ in a neighborhood of $p=1$, since $\lim _{p !} \frac{d^{2} M}{1(d p)^{2}}<0$.

Corollary 1

By optimality of factor employment in the ..nal good sector, $K_{Y}={ }_{\mathrm{n}} Y \mathrm{f} \frac{\mathrm{h}}{r\left(1_{\mathrm{i}} \alpha\right)}{ }_{1_{\mathrm{i}} \alpha}$, which can be re-written, after substituting $Y$ with $Y^{D}$, as $K_{Y}=\mathrm{i} \frac{2+r+\beta}{1+\beta}{ }^{\mathrm{n}} G\left(\pi^{\ltimes}\right) B \chi+{ }_{\pi^{\text {ळ }}} \mathrm{f}[\pi+$ $\left.\left(\begin{array}{ll}1 & \pi\end{array}\right) \varphi\right] A g(\pi) d \pi \mathbf{i} r$, with $\mathbf{i}={\frac{\alpha}{r\left(1_{\mathrm{i} \alpha}\right)}}^{\mathrm{i}} 1_{\mathrm{i} \alpha}$. The ..rst derivative of $\frac{M}{F}$ w.r.t. $p$ is

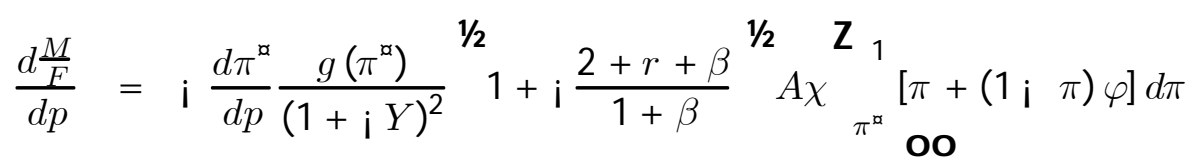

$$
\begin{aligned}
& \text { i }\left[1 \text { i } G\left(\pi^{\not}\right)\right] A \chi\left[\pi^{\not \alpha}+\left(1 \text { i } \pi^{\ltimes}\right) \varphi\right]+B \chi \text { i } r \text {, }
\end{aligned}
$$

Risk-sharing ..nance as a ratio of total external ..nance is increasing in investor protection, $\frac{d \frac{M}{F}}{d p}, 0$ for any $p 2[0,1]$, since $\frac{d \pi^{\infty}}{d p} \cdot 0$ and the term in brackets is always positive. To prove concavity of $\frac{M}{F}$ in a neighborhood of $p=1$, I derive

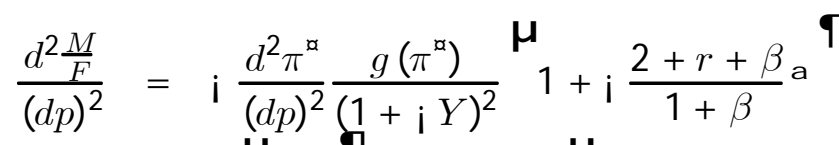

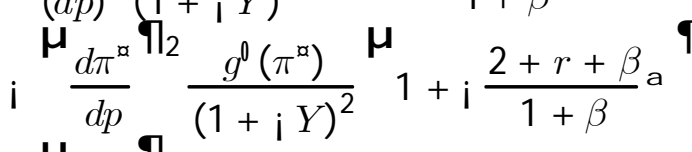

$$
\begin{aligned}
& +\frac{d \pi^{\infty}}{d p} \frac{g\left(\pi^{\infty}\right)}{(1+\mathrm{i} Y)^{2}} \mathrm{i} \frac{2+r+\beta}{1+\beta} \underline{\mathrm{a}}\left[1 \mathrm{i} G\left(\pi^{\propto}\right)\right] A \chi(1 \mathrm{i} \varphi) \\
& \mathrm{i} 2{\frac{d \pi^{\alpha}}{d p}}^{\text {ी }_{2}} \frac{g\left(\pi^{\alpha}\right)^{2}}{(1+\mathrm{i} Y)^{3}} 1+\mathrm{i} \frac{2+r+\beta}{1+\beta} a^{\text {ी }} \mathrm{i} \frac{2+r+\beta}{1+\beta}
\end{aligned}
$$

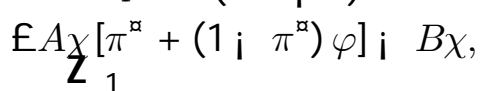

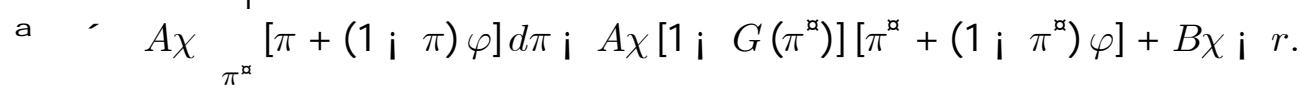


As $\lim _{p ! 1} \frac{d \pi^{\star}}{d p}=0$, while $\frac{d^{2} \pi^{\alpha}}{(d p)^{2}}>0$ at any $p, \lim _{p !} \frac{d^{2} \frac{M}{F}}{(d p)^{2}}<0$.

\section{Lemma 3}

To prove non monotonicity, I dixerentiate $\operatorname{Var}(w)$ with respect to $p$ :

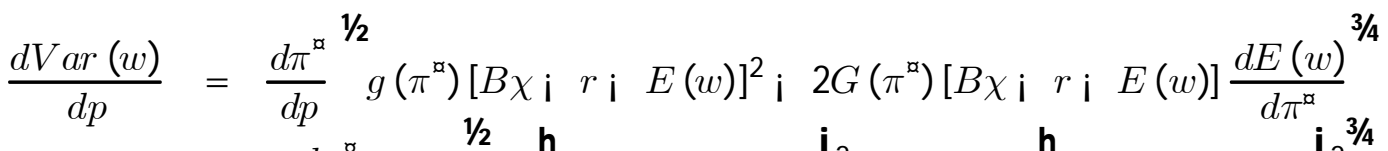

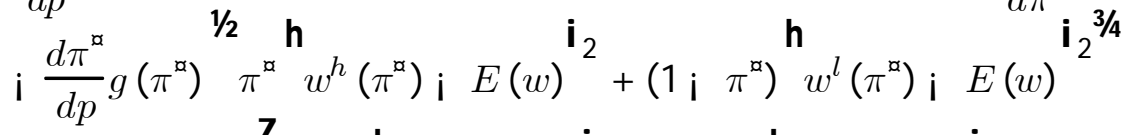

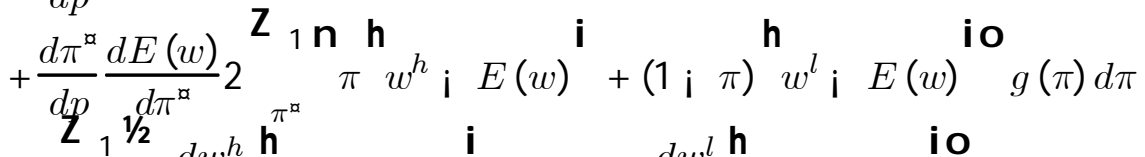

$$
\begin{aligned}
& +2{ }_{\pi^{\natural}}^{\sum_{1}} \pi \frac{d w^{h}}{d p} w^{\pi^{\natural}} \mathbf{i} E(w)^{\mathbf{i}}+(1 \mathbf{i} \pi) \frac{d w^{l}}{d p} w^{l} \mathbf{i} E(w)^{\text {i o }} g(\pi) d \pi
\end{aligned}
$$

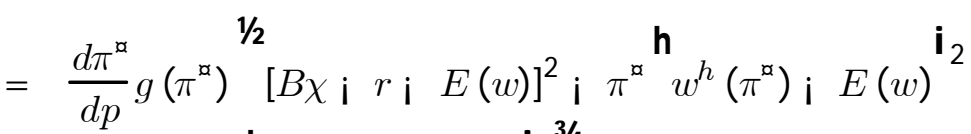

$$
\begin{aligned}
& \text { i }\left(1 ; \pi^{\ltimes}\right) w^{l}\left(\pi^{\mathfrak{\alpha}}\right) ; \quad E(w) \mathbf{i}^{3 / 4} \\
& \text { i } 2(1 \text { i } \varphi) A \chi_{\pi^{\natural}}^{Z_{1}} \pi(1 \text { i } \pi)^{3} w^{h} \mathbf{i} w^{l} g(\pi) d \pi \text {. }
\end{aligned}
$$

Notice that the term in the ..rst two lines represents the market size exect and is positive for all $p$, while the last line accounts for the risk sharing exect and is negative for all $p$.

For $p ! 0, \pi^{\ltimes} ! 1, E(w) ! B \chi \mathbf{i} r, w^{h} ! A \chi \mathbf{i} r, w^{l} ! \varphi A \chi \mathbf{i} r$. Therefore,

$$
\lim _{p ! 0} \frac{d \operatorname{Var}(w)}{d p}=\mathbf{i} \frac{d \pi^{\ltimes}}{d p} g(1)(A \mathbf{i} B)^{2} \chi^{2}>0 .
$$

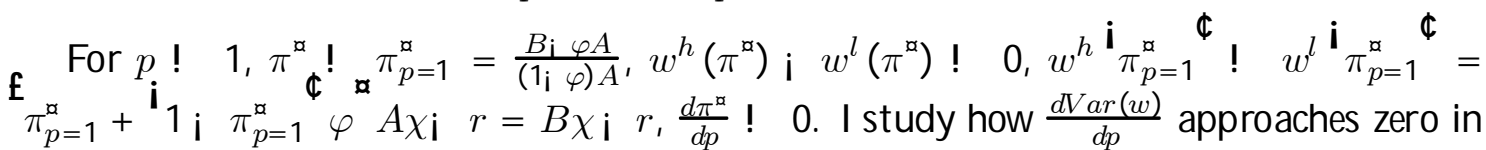
a left neighborhood of $p=1$ by means of Taylor's ..rst-order approximation. Notice that 


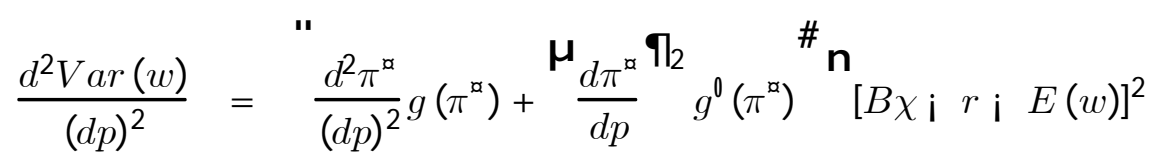

$$
\begin{aligned}
& \text { i } \pi^{\mathrm{\alpha}} w^{h}\left(\pi^{\alpha}\right) \text { i } E(w)^{\mathbf{i}_{2}} \text { i }\left(1 ; \pi^{\alpha}\right) w^{l}\left(\pi^{\alpha}\right) \text { i } E(w)^{\mathbf{i}_{2}^{3 / 4}}
\end{aligned}
$$

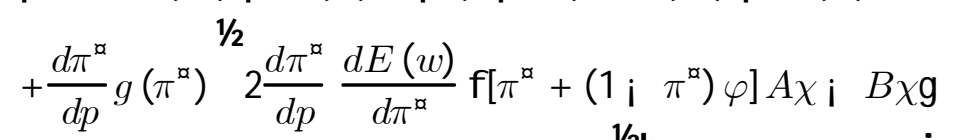

$$
\begin{aligned}
& +2 \pi^{\ltimes}\left(1 \mathbf{i} \pi^{\ltimes}\right)(1 ; \quad \varphi)^{2}(A \chi)^{2} \mathbf{i} \frac{d \pi^{\ltimes}}{d p} w^{h}\left(\pi^{\ltimes}\right) ; \quad E(w)^{\mathbf{i}_{2}}
\end{aligned}
$$

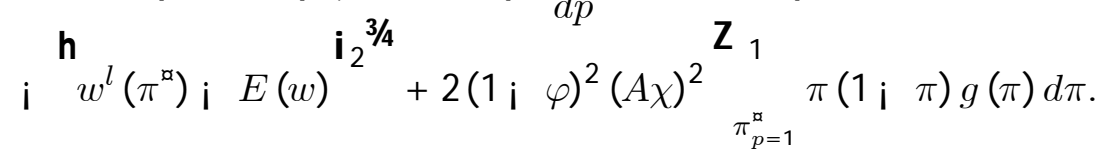

It follows that, in a neighborhood to the left of $p=1$,

$$
\frac{d \operatorname{Var}(w)}{d p}=2(p \text {; } 1)(1 \text {; } \varphi)^{2}(A \chi)^{2}{ }_{\pi_{p=1}^{\sharp}}^{Z_{1}} \pi(1 \text {; } \pi) g(\pi) d \pi<0 .
$$

\section{Proposition 2}

Recall from Proposition 1 that $M$ is increasing in $p$. I characterize the relationship between the size of the risk-sharing market and the variance of earnings by studying

$$
\begin{aligned}
& \frac{d \operatorname{Var}(w)}{d M}=\frac{d \operatorname{Var}(w)}{d p}^{\mu} \frac{d M}{d p}^{\boldsymbol{\bigcap}_{\mathrm{i}} 1} \\
& =\mathbf{i}[B \chi \mathbf{i} r \mathbf{i} E(w)]^{2}+\left(1 ; \quad \pi^{\text {ळ}}\right) w^{l}\left(\pi^{\text {ळ}}\right) \mathbf{i} E(w)^{\mathbf{i}_{2}}
\end{aligned}
$$

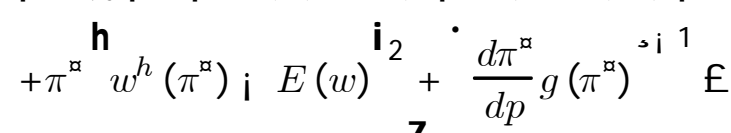

$$
\begin{aligned}
& \mathrm{Z}_{1} \\
& 2(1 \text { i } \varphi)^{2}(A \chi)^{2}(1 \text { i } p)_{\pi^{\natural}}^{1} \pi(1 \text { i } \pi) g(\pi) d \pi
\end{aligned}
$$

For $p ! 0, \pi^{\ltimes} ! 1, E(w) ! B \chi \mathbf{i} r, w^{h} ! A \chi \mathbf{i} r, w^{l} ! \varphi A \chi \mathbf{i} r$, hence

$$
\lim _{p !} \frac{d \operatorname{Var}(w)}{d M}=(A \mathrm{i} B)^{2} \chi^{2}>0
$$

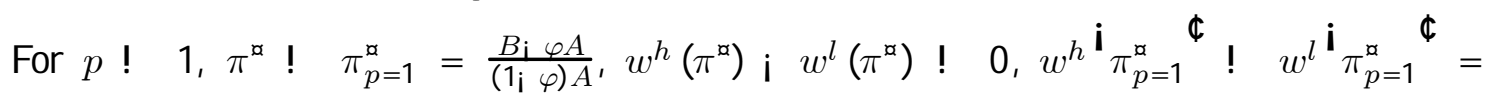




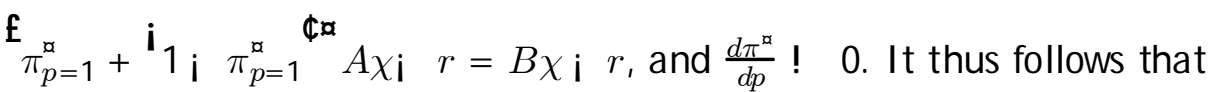

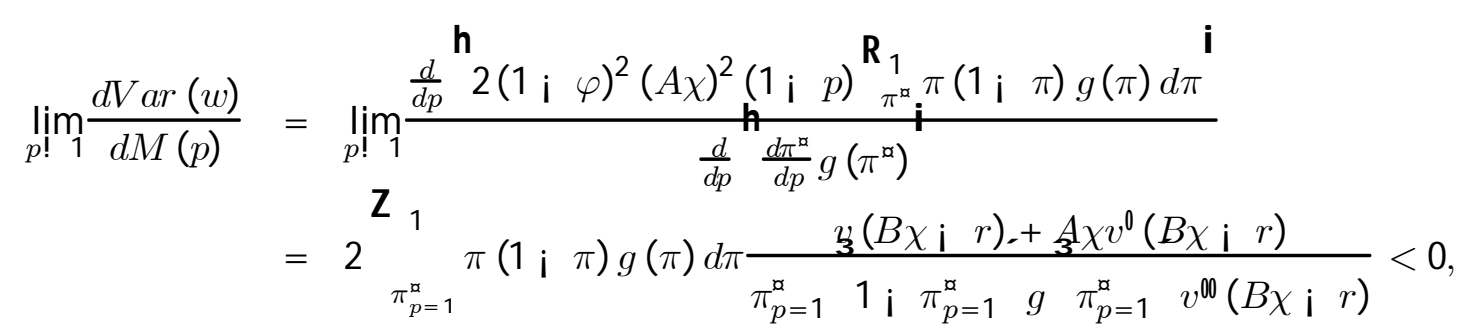

since $v^{\varpi}<0$ for any CRRA utility function.

\section{B Closed economy}

In this section, I show how the economy can be closed without axecting the main results discussed in sections 2 and 3. A ssume that capital and intermediate goods can no longer be imported or exported. It follows that their prices will be pinned down by domestic demand and supply: $r_{t}=\alpha \frac{Y_{t}}{K_{Y t}}$, and $\chi_{t}=(1 \mathrm{i} \alpha) \frac{Y_{t}}{X_{t}}$. Further, capital will follow the law of motion:

$$
K_{t+1}=\frac{1}{1+\beta} G\left(\pi_{t}^{\natural}\right) B \chi_{t}+A \chi_{t}{ }_{\pi_{t}^{\alpha}}[\pi+(1 \mathbf{i} \pi) \varphi] g(\pi) d \pi \mathbf{i} r_{t},
$$

where the RHS is aggregate savings. Aggregate capital is allocated between the ..nal and the intermediate good sectors:

$$
K_{t+1}{ }^{\prime} K_{Y t+1}+1 \text {. }
$$

The aggregate supply of intermediate goods, $X_{t}$, equals total production of safe and risky projects:

$$
X_{t}=G\left(\pi_{t}^{\mathfrak{a}}\right) B+A_{\pi_{t}^{\mathfrak{\natural}}}^{\mathbf{Z}_{1}}[\pi+(1 \mathbf{i} \pi) \varphi] g(\pi) d \pi .
$$

Notice that the production of intermediate goods $X_{t}$ is decreasing in the threshold ability $\pi_{t}^{\alpha}$. Optimal technology adoption maintains the threshold property of Lemma 1 , since agents take prices as given and the risky payous are still increasing in ability. In any period, the threshold ability $\pi_{t}^{\alpha}$ satis..es:

$$
\pi_{t}^{\mathrm{\alpha}} v^{3} w_{t}^{h}\left(\pi_{t}^{\mathrm{\alpha}}\right), r_{t+1}+\left(1 \mathbf{i} \pi_{t}^{\mathrm{\alpha}}\right) v^{3} w_{t}^{l}\left(\pi_{t}^{\mathrm{\alpha}}\right), r_{t+1}=v\left(B \chi_{t} \mathbf{i} r_{t}, r_{t+1}\right) .
$$

Equations (9) and (8) characterize the dynamic equilibrium. In the next sections, I report numerical solutions for the steady stateand the transition dynamics. In particular, I show that Lemmas 2-3 and Propositions 1-2 continue to hold in the steady state. Moreover, along the transition between steady states with dixerent investor protection, the size of 
the risk-sharing market converges monotonically. Income inequality may instead converge along an oscillatory path, as a consequence of the dynamics of prices and capital.

\section{B.1 The dynamics}

The dynamics of the closed economy satis..es equations (??) and (9):

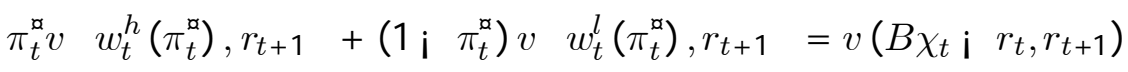

$$
\begin{aligned}
& K_{t+1}=\frac{1}{1+\beta} G\left(\pi_{t}^{\text {风) }} B \chi_{t}+A \chi_{t}{ }_{\pi_{t}^{\mathrm{a}}}^{\mathbf{Z}_{1}}\left[\pi+\left(\begin{array}{ll}
1 \mathrm{i} & \pi
\end{array}\right) \varphi\right] g(\pi) d \pi \mathrm{i} r_{t}\right)
\end{aligned}
$$

Dixerently from the small open economy, equilibrium earnings $w_{t}\left(\pi_{i}\right)$ now depend also on factor prices, that are functions of the threshold ability $\left(\pi_{t}^{\mathfrak{a}}\right)$, and of thecapital employed in the ..nal sector ( $\left.K_{Y t}=K_{t} \mathbf{i} 1\right)$. G iven $K_{t}$ (which is predetermined), an increase in the hiding cost $p$ raises the left-hand side of equation (9), which would determine a drop in the threshold ability $\pi^{\mathrm{\alpha}}$. A lower threshold would in turn imply an increase in the production of intermediate goods $\left(X_{t}\right)$ and in the demand of capital in the ..nal good sector $\left(\mathrm{K}_{Y t}\right)$, and therefore a drop in the price of intermediate goods $\left(\chi_{t}\right)$ and a rise in the interest rate $\left(r_{t}\right)$. These changes in factor prices would feed back into equation (9), reducing both the left and the right-hand sides. In general equilibrium, the overall exect on the threshold depends on which side drops more. N otice however, that under perfect investor protection the threshold ability does not depend on relative factor prices, since $\pi_{p=1}^{\alpha}=\frac{A_{i} B}{\left(1_{i} \varphi\right) A}$.

Since the analytical characterization of the dynamic equilibrium becomes awkward, I proceed by means of numerical solutions. The main results are displayed in Figures 4-6. In all simulations, I adopt the following parametrization: $A=150, B=100, \alpha=0.33$, $\beta=0.17$ (equivalent to a six per cent annual discount for thirty years, i.e. a generation), and $G$ uniform in $[0,1]$.

Notice that, in the absence of investor protection, a minimum initial capital is required in order for production of the intermediate good, and hence of the ..nal good too, to be feasible: $K_{0}>\frac{1}{1_{\mathrm{i} \alpha} \alpha}$ (which makes sure that $B \chi\left(\pi^{\ltimes}=1\right)>r\left(\pi^{\ltimes}=1\right)$ ). Also, even in under perfect investor protection ( $p=1$ ), no young agent chooses the risky technology if capital is so scarce that the repayment due by an entrepreneur with ability 1 exceeds her cash fow: $K<\frac{\alpha}{1_{\mathrm{i}} \alpha} \frac{B}{A}$ (which makes sure that $A \chi\left(\pi^{\alpha}=1\right)>r\left(\pi^{\alpha}=1\right)$ ). Given that $\alpha=0.33$, at $p=1$ there is a non-zero market for risk sharing, whenever capital satis..es $K>\frac{1}{1_{\mathrm{i}} \alpha}$.

Figure 4 describes the dynamics of an economy that starts with a very low capital endowment, $K_{0}=0.5+\frac{1}{1_{\mathrm{i} \alpha} \alpha}$, and an intermediate degree of investor protection, $p=0.5$. When $K_{0}$ is very low, the interest rate is so high relative to the price of the intermediate 
good that no young agent chooses the risky technology. Hence, the market for risk sharing is inactive and inequality is zero. As capital is accumulated, the interest rate falls and the price of intermediates rises. When the ratio $r / \chi$ becomes low enough, some young agents prefer the risky project and raise capital through the risk-sharing market. This implies that some income inequality arises due to the "market size" exect, as in the model of sections 2-3. The adjustment of capital and prices continues until the steady state is reached. Decreasing marginal productivity of capital guarantees the existence of the steady state.

Notice that the price of intermediate goods $(\chi)$ axects inequality also by changing the earnings dixerentials between safe and risky entrepreneurs. The higher $\chi$, the wider the earnings dixerentials, the higher inequality ("price" exect). This implies that, with endogenous prices, inequality may vary even if stock market size does not.

Figure 5 shows the adjustment after a policy change that increases investor protection from $p=0$ to $p=0.05$, starting from the steady state. Due to the convexity of $\pi_{t}^{\mathrm{d}}$ in $p$, the risky intermediate sector expands remarkably in response to the policy change. The marginal productivity of capital in the ..nal sector rises sharply because the production of intermediates increases. This causes an overshooting of the interest rate, that gradually declines with capital accumulation to its new (higher) steady state level. Inequality immediately jumps up and oscillates around its new (higher) steady state level until capital and prices are stable.

If the policy change occurs at high levels of investor protection, as shown in ..gure 6 for $p$ from 0.85 to 0.9 , the exect on productivity of factors (hence prices) is weaker. An increase in $p$ induces a small increase in the size of the risky intermediate sector, and has virtually no exect on the interest rate. Inequality falls, since the "risk sharing" exect outweighs the "market size" exect at high levels of investor protection.

\section{B.2 The steady state}

In the steady state, $K_{t+1}=K_{t}=K$ and $\pi_{t+1}^{\alpha}=\pi_{t}^{\alpha}=\pi^{\alpha}$. The equilibrium is the solution to the system:

$$
\begin{aligned}
& V V, \quad \pi^{\circledR} v w^{h}\left(\pi^{\ltimes}\right), r+\left(1 \mathbf{i} \pi^{\ltimes}\right) v^{3} w^{l}\left(\pi^{\ltimes}\right), r \quad \mathbf{i} \quad v(B \chi \mathbf{i} \quad r, r)=0 \\
& K K^{\prime} \quad(1+\beta) K \mathbf{i} G\left(\pi^{\ltimes}\right)(B \chi \mathbf{i} r) \mathbf{i}_{\pi^{\natural}} \mathbf{Z}_{1 \mathbf{h}} \pi w^{h}(\pi)+\left(\begin{array}{ll}
1 & \pi
\end{array}\right) w^{l}(\pi)^{\mathbf{i}} g(\pi) d \pi=0 .
\end{aligned}
$$

In the presence of perfect investor protection, the threshold ability does not depend on factor prices and is equal to $\frac{B \mathrm{i} \varphi A}{\left(1_{\mathbf{i}} \varphi\right) A}$ as in the small open economy. Figure 7 plots the comparative statics for all levels of investor protection $p 2[0,1]$ in the steady state, which 

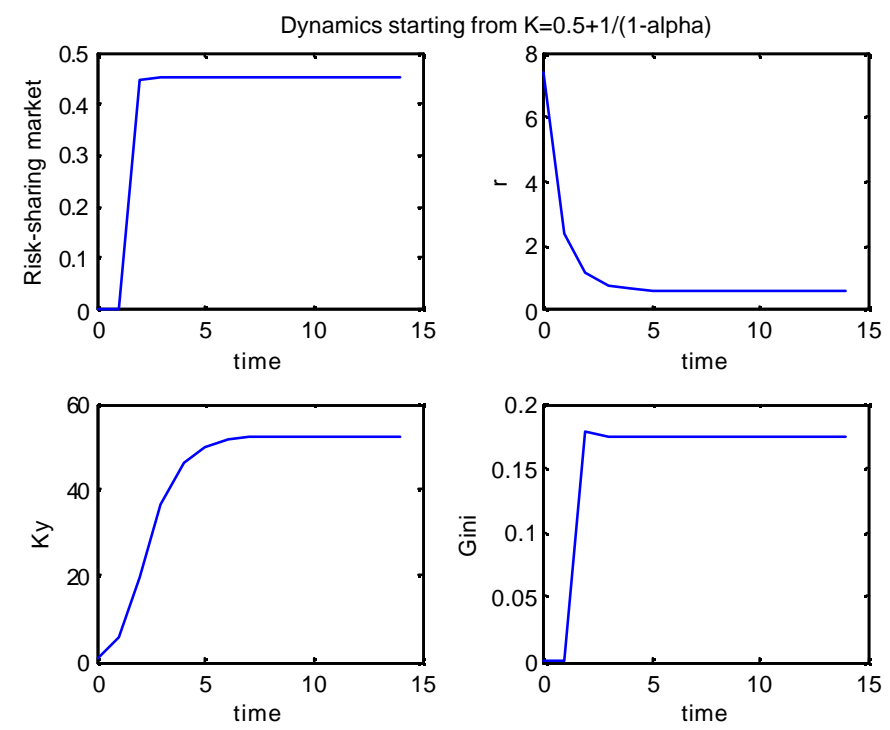

Figure 4: Dynamics from a low initial capital endowment $\left(K=0.5+\frac{1}{1_{i} \alpha}\right)$ to the steady state, given $p=0.5$.
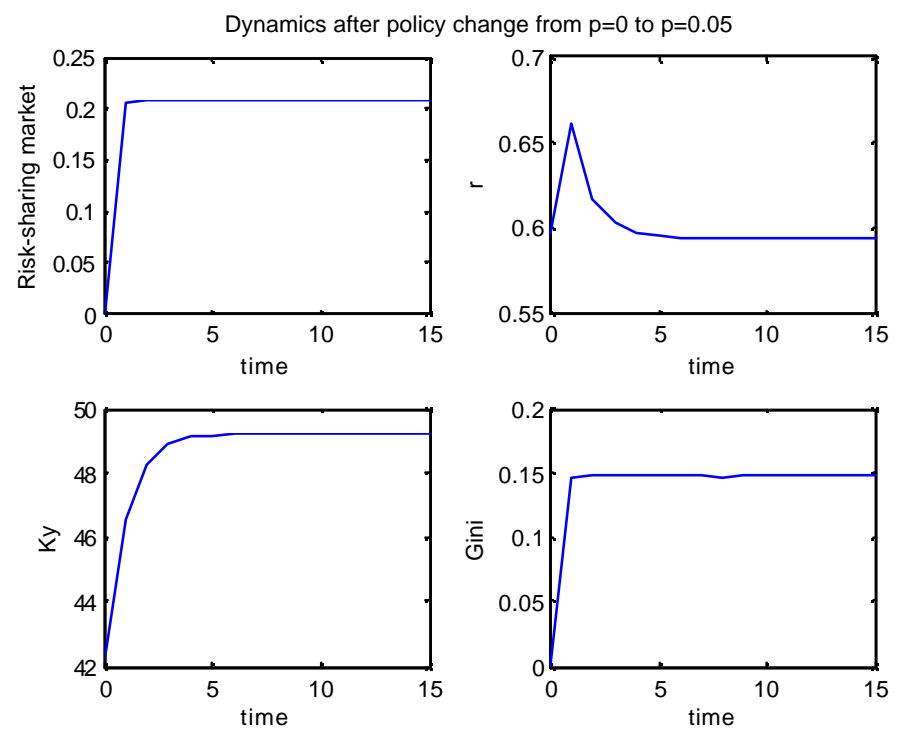

Figure 5: Dynamic adjustment after a policy change from $p=0$ to $p=0.05$. 

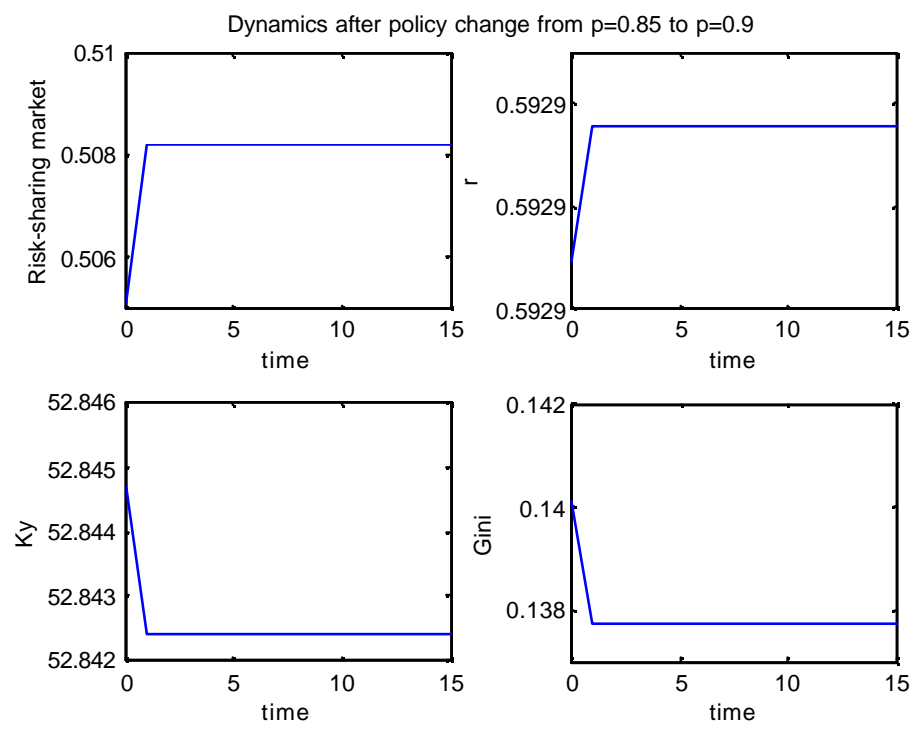

Figure 6: Dynamic adjustment after a policy change from $p=0.85$ to $p=0.9$.
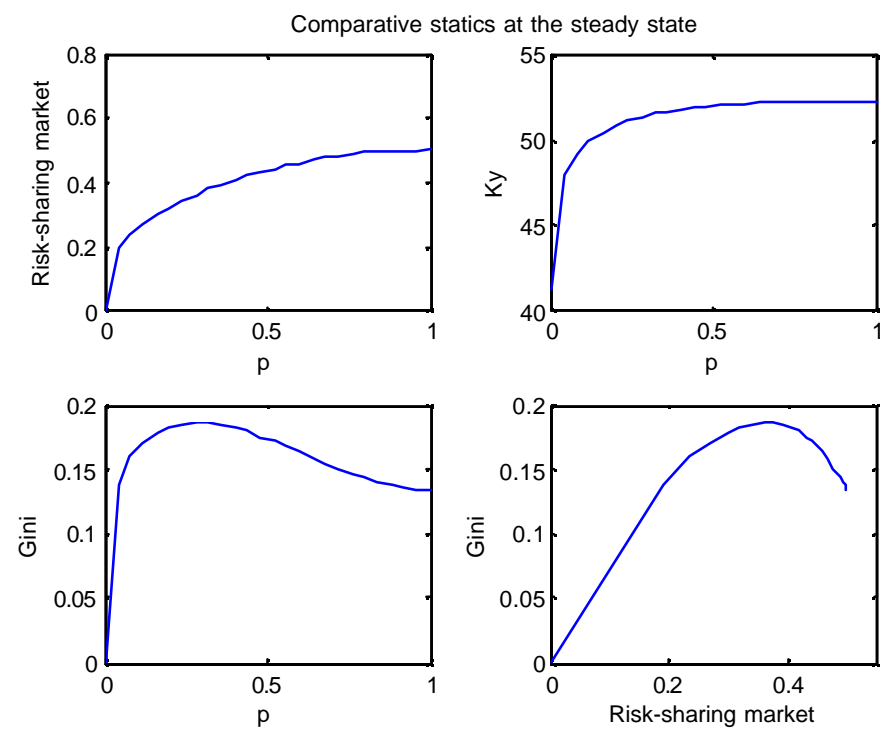

Figure 7: Comparative statics for varying investor protection across steady states. 
shows that Lemmas 1-3 and Propositions 1-2 continue to hold in the closed economy. In fact, the "price" exect, that axects inequality along the dynamics, is irrelevant in the steady state. Therefore, the comparative statics on investor protection is driven by the "market size" and "insurance" exects only, as in the small open economy.

\section{Simul at ion det ails}

This section describes step by step the procedure I followed for simulating the small open economy of section 2 and 3 (and the closed economy in the previous section of the A ppendix).

1. Give values for the main parameters $(A, B, \varphi, \beta, \alpha)$ and the interest rate, and compute the threshold ability with perfect investor protection ${ }^{\alpha} \pi_{p=1}^{\alpha}$.

2. Compute values for the parameters of the Lognormal distribution of abilities, $(\mu, \sigma)$, from B arro and Lee's (2000) data. The database provides observations for the percentages of the population aged 15 and above with no, primary, secondary and tertiary education $(l u, l p, l s, l h)$, along with the average year of each education level $($ pyr, syr, hyr $)$. I compute the average years of schooling for people with primary, secondary and tertiary education $\left(q_{1}, q_{2}, q_{3}\right.$, respectively):

$$
q_{1}=\frac{p y r}{l p+l s+l h} ; q_{2}=q_{1}+\frac{s y r}{l s+l h} ; q_{3}=q_{1}+q_{2}+\frac{h y r}{l h} .
$$

The average years of schooling and their variance are then

$$
\begin{aligned}
E(Q) & =\mathrm{X}_{i=1}^{3} l_{i} q_{i} \\
V(Q) & =\mathrm{X}_{i=0}^{\mathrm{3}} l_{i}\left(q_{i} \mathrm{i} E(Q)\right)^{2},
\end{aligned}
$$

with $l_{0}=l u, l_{1}=l p, l_{2}=l s$ and $l_{3}=l h$. Group the countries in low-income, middle-income and high-income following the WDI criterion and take the average values of $E(Q)$ and $V(Q)$. Finally, $\mu$ and $\sigma$ can be derived from the expressions for mean and variance of the Lognormal distribution:

$$
\begin{aligned}
& E(Q)=e^{\mu+\frac{\sigma^{2}}{2}} \\
& V(Q)=e^{2 \mu+2 \sigma^{2}} \mathrm{i} e^{\mu+\sigma^{2}} .
\end{aligned}
$$

3. De..ne a grid of 101 degrees of investor protection $p 2[0,1]$, and a grid of initial 
guesses for the threshold ability $\pi^{\not} 2{ }_{\pi_{p=1}^{\alpha}, 1}^{\mathfrak{\alpha}}$, equally spaced by 0.0001 (the ..ner the grid, the better the approximation).

4. Draw $1=10001$ ability levels from a Lognormal $(\mu, \sigma)$ and sort them in ascending order. Identify the ability level $\pi .9995: G(\pi .9995)=0.9995$ and divide every $\pi \cdot \pi .9995$ by this ..gure. Replace all $\pi>\pi .9995$ by 1 , so that the distribution is normalized to values included in $[0,1]$, and truncated in a way that makes the top 0.05 per cent of the population successful with certainty. Compute the Cdf of ability,

$$
G\left(\pi_{i}\right)=\frac{\# \text { of realizations } \pi \cdot \pi_{i}}{\mathrm{i}}
$$

5. For every degree of investor protection $p$

(a) compute $\pi^{\infty}(p)$ as the solution to the technology choice problem. In particular, recursively ...nd the point in the grid of $\pi^{\ltimes}$ satisfying:

$$
\begin{aligned}
\log (B \mathbf{i} r) & =\pi^{\infty} \log w^{h}+\left(1 \mathbf{i} \pi^{\ltimes}\right) \log w^{l} \\
w^{h} & =A\left[\pi^{\infty} p(1 \mathbf{i} \varphi)+\varphi+(1 \mathbf{i} p)(1 \mathbf{i} \varphi)\right] \mathbf{i} r \\
w^{l} & =A\left[\pi^{\ltimes} p(1 \mathbf{i} \varphi)+\varphi\right] \mathbf{i} r>0 .
\end{aligned}
$$

(b) For every ability $\pi$

i. draw the earning realization:

$$
\begin{array}{ccc}
w= & B \mathbf{i} r & \pi<\pi^{\alpha} \\
\epsilon \gg & A\left[\pi^{\alpha} p(1 \mathbf{i} \varphi)+\varphi+(1 \mathbf{i} p)(1 \mathbf{i} \varphi) \epsilon\right] \mathbf{i} r & \pi, \pi^{\alpha} \\
& B i(N, \pi) \text {, with } N=\# \text { of } \pi, \pi^{\alpha} . &
\end{array}
$$

ii. sort $w$ and derive its cumulative density function as $F\left(w_{i}\right)=\frac{\# \text { of realizations } w \cdot w_{i}}{i}$

iii. compute the Lorenz Curve as $L\left(w_{m}\right)=\frac{\text { mean of } w \cdot w_{m}}{\text { megn of } w} \frac{m}{1}$ for $m=1,2, \ldots$.

iv. compute the Gini coec cient as Gini $=1 \mathrm{i} 2{ }_{m=1} \frac{L\left(w_{m}\right)}{\mathrm{i}}$

(c) save the threshold and the G ini in ( $1 £ p$ ) vectors, $1 / 2(p)$ and $\operatorname{Gini}(p)$, the earnings realizations, their distribution and the Lorenz curve in $(p £ \mid)$ matrices, $\mathbf{w}(p, \pi), \mathbf{F}(p, w(p, \pi))$ and $\mathrm{L}(p, w(p, \pi))$

When simulating the closed economy, step 1 does not specify $r$.

Step 5.(a) ...nds the threshold ability $\pi_{t}^{\alpha}(p)$ which solves (10) for a given initial capital

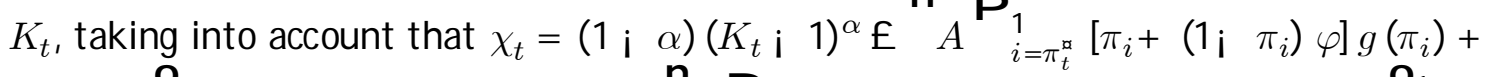

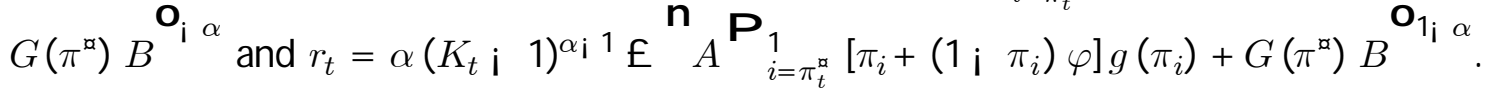


After step 5.(c), capital in the next period is computed as $K_{t+1}={ }_{i=0}^{P_{1}} w_{i} \mathbf{i} \quad r$ and plugged into step 5.a. as new initial capital $K_{t}$. This recursion goes on until the steady state is reached and $K_{t}=K_{t+1}$. 
Table A

Countries and Samples

\begin{tabular}{|c|c|c|c|c|c|c|c|c|c|}
\hline Country & $\mathrm{CL}$ & $\mathrm{CS}$ & $\mathrm{PL}$ & $\mathrm{PS}$ & Country & $\mathrm{CL}$ & $\mathrm{CS}$ & PL & PS \\
\hline Australia & $\mathrm{y}$ & $\mathrm{y}$ & $\mathrm{y}$ & $\mathrm{y}$ & Kenya & $\mathrm{y}$ & $\mathrm{y}$ & & \\
\hline Austria & $\mathrm{y}$ & & & & Korea & $\mathrm{y}$ & $\mathrm{y}$ & $\mathrm{y}$ & $\mathrm{y}$ \\
\hline Bangladesh & $\mathrm{y}$ & & $\mathrm{y}$ & $\mathrm{y}$ & Malaysia & $\mathrm{y}$ & $\mathrm{y}$ & $\mathrm{y}$ & $\mathrm{y}$ \\
\hline Barbados & $\mathrm{y}$ & & & & Mauritius & $\mathrm{y}$ & & $\mathrm{y}$ & \\
\hline Belgium & $\mathrm{y}$ & $\mathrm{y}$ & $\mathrm{y}$ & & Mexico & $\mathrm{y}$ & $\mathrm{y}$ & $\mathrm{y}$ & $\mathrm{y}$ \\
\hline Bolivia & $\mathrm{y}$ & & & & Nepal & $\mathrm{y}$ & & & \\
\hline Botswana & $\mathrm{y}$ & & & & Netherlands & $\mathrm{y}$ & $\mathrm{y}$ & $\mathrm{y}$ & $\mathrm{y}$ \\
\hline Bulgaria & & & $\mathrm{y}$ & & New Zealand & $\mathrm{y}$ & $\mathrm{y}$ & $\mathrm{y}$ & $\mathrm{y}$ \\
\hline Brazil & $\mathrm{y}$ & $\mathrm{y}$ & $\mathrm{y}$ & $\mathrm{y}$ & Norway & $\mathrm{y}$ & $\mathrm{y}$ & $\mathrm{y}$ & $\mathrm{y}$ \\
\hline Canada & $\mathrm{y}$ & $\mathrm{y}$ & $\mathrm{y}$ & $\mathrm{y}$ & Pakistan & $\mathrm{y}$ & $\mathrm{y}$ & $\mathrm{y}$ & $\mathrm{y}$ \\
\hline Chile & $\mathrm{y}$ & $\mathrm{y}$ & $\mathrm{y}$ & & Panama & $\mathrm{y}$ & & & \\
\hline China & $\mathrm{y}$ & & $\mathrm{y}$ & & Paraguay & $\mathrm{y}$ & & & \\
\hline Colombia & $\mathrm{y}$ & $\mathrm{y}$ & $\mathrm{y}$ & & Peru & $\mathrm{y}$ & $\mathrm{y}$ & $\mathrm{y}$ & $\mathrm{y}$ \\
\hline Costa Rica & $\mathrm{y}$ & & $\mathrm{y}$ & $\mathrm{y}$ & Philippines & $\mathrm{y}$ & $\mathrm{y}$ & $\mathrm{y}$ & \\
\hline Denmark & $\mathrm{y}$ & $\mathrm{y}$ & $\mathrm{y}$ & $\mathrm{y}$ & Poland & $\mathrm{y}$ & & $\mathrm{y}$ & $\mathrm{y}$ \\
\hline Ecuador & $\mathrm{y}$ & $\mathrm{y}$ & $\mathrm{y}$ & & Portugal & $\mathrm{y}$ & $\mathrm{y}$ & $\mathrm{y}$ & \\
\hline Egypt & $\mathrm{y}$ & $\mathrm{y}$ & $\mathrm{y}$ & & Romania & $\mathrm{y}$ & & & \\
\hline El Salvador & $\mathrm{y}$ & & & & Russia & & & $\mathrm{y}$ & $\mathrm{y}$ \\
\hline Finland & $\mathrm{y}$ & $\mathrm{y}$ & $\mathrm{y}$ & $\mathrm{y}$ & Singapore & $\mathrm{y}$ & $\mathrm{y}$ & $\mathrm{y}$ & $\mathrm{y}$ \\
\hline France & $\mathrm{y}$ & $\mathrm{y}$ & $\mathrm{y}$ & $\mathrm{y}$ & Slovak Republic & & & $\mathrm{y}$ & \\
\hline Germany & $\mathrm{y}$ & $\mathrm{y}$ & $\mathrm{y}$ & $\mathrm{y}$ & South Africa & $\mathrm{y}$ & $\mathrm{y}$ & & \\
\hline Ghana & $\mathrm{y}$ & & $\mathrm{y}$ & $\mathrm{y}$ & Spain & $\mathrm{y}$ & $\mathrm{y}$ & $\mathrm{y}$ & $\mathrm{y}$ \\
\hline Greece & $\mathrm{y}$ & & $\mathrm{y}$ & & Sri Lanka & $\mathrm{y}$ & $\mathrm{y}$ & $\mathrm{y}$ & $\mathrm{y}$ \\
\hline Guatemala & $\mathrm{y}$ & & & & Sweden & $\mathrm{y}$ & $\mathrm{y}$ & $\mathrm{y}$ & $\mathrm{y}$ \\
\hline Honduras & $\mathrm{y}$ & & & & Switzerland & $\mathrm{y}$ & & & \\
\hline Hong Kong & $\mathrm{y}$ & $\mathrm{y}$ & $\mathrm{y}$ & $\mathrm{y}$ & Taiwan & $\mathrm{y}$ & $\mathrm{y}$ & $\mathrm{y}$ & $\mathrm{y}$ \\
\hline Hungary & $\mathrm{y}$ & & $\mathrm{y}$ & & Thailand & $\mathrm{y}$ & $\mathrm{y}$ & $\mathrm{y}$ & $\mathrm{y}$ \\
\hline India & $\mathrm{y}$ & $\mathrm{y}$ & $\mathrm{y}$ & $\mathrm{y}$ & Trinidad and Tobago & $\mathrm{y}$ & & $\mathrm{y}$ & $\mathrm{y}$ \\
\hline Indonesia & $\mathrm{y}$ & $\mathrm{y}$ & $\mathrm{y}$ & $\mathrm{y}$ & Tunisia & $\mathrm{y}$ & & $\mathrm{y}$ & \\
\hline Iran & $\mathrm{y}$ & & & & Turkey & $\mathrm{y}$ & $\mathrm{y}$ & $\mathrm{y}$ & \\
\hline Ireland & $\mathrm{y}$ & & & & United Kingdom & $\mathrm{y}$ & $\mathrm{y}$ & $\mathrm{y}$ & $\mathrm{y}$ \\
\hline Israel & $\mathrm{y}$ & $\mathrm{y}$ & & & United States & $\mathrm{y}$ & $\mathrm{y}$ & $\mathrm{y}$ & $\mathrm{y}$ \\
\hline Italy & $\mathrm{y}$ & $\mathrm{y}$ & $\mathrm{y}$ & $\mathrm{y}$ & Uruguay & $\mathrm{y}$ & $\mathrm{y}$ & & \\
\hline Jamaica & $\mathrm{y}$ & & $\mathrm{y}$ & & Venezuela & $\mathrm{y}$ & $\mathrm{y}$ & $\mathrm{y}$ & $\mathrm{y}$ \\
\hline Japan & $\mathrm{y}$ & $\mathrm{y}$ & $\mathrm{y}$ & $\mathrm{y}$ & Zambia & $\mathrm{y}$ & & & \\
\hline Jordan & $\mathrm{y}$ & $\mathrm{y}$ & $\mathrm{y}$ & $\mathrm{y}$ & Zimbabwe & $\mathrm{y}$ & $\mathrm{y}$ & & \\
\hline
\end{tabular}

Note: $\mathrm{C}$ and $\mathrm{P}$ stand for cross-sectional and panel datasets, respectively.

$\mathrm{L}$ and $\mathrm{S}$ for large and small samples. 
Table 1. Risk-sharing market and income inequality OLS - cross-section - 1980-2000

\begin{tabular}{|c|c|c|c|c|c|c|}
\hline & 1 & 2 & 3 & 4 & 5 & 6 \\
\hline \multirow[t]{2}{*}{ Smpr } & .038 & $.142 * *$ & & .035 & $.142 * *$ & $.141^{* *}$ \\
\hline & $(.029)$ & $(.032)$ & & $(.029)$ & $(.032)$ & $(.033)$ \\
\hline \multirow[t]{2}{*}{ Smpr ${ }^{2}$} & & $-.033 * *$ & & & $-.034 * *$ & $-.034 * *$ \\
\hline & & $(.008)$ & & & $(.008)$ & $(.008)$ \\
\hline \multirow[t]{2}{*}{ Smcap } & & & $.252 * *$ & & & \\
\hline & & & $(.085)$ & & & \\
\hline \multirow[t]{2}{*}{ Smcap $^{2}$} & & & $-.069 *$ & & & \\
\hline & & & $(.036)$ & & & \\
\hline \multirow[t]{2}{*}{ Privo } & & & $-.089 *$ & & & \\
\hline & & & (.049) & & & \\
\hline \multirow[t]{2}{*}{$\operatorname{Sec} 25$} & $-.185^{* *}$ & $-.197 * *$ & $-.214 * *$ & & & -.133 \\
\hline & (.056) & $(.052)$ & $(.063)$ & & & $(.085)$ \\
\hline \multirow[t]{2}{*}{ Gh_15 } & & & & $.114^{*}$ & $.149 * *$ & .070 \\
\hline & & & & $(.058)$ & $(.061)$ & $(.086)$ \\
\hline \multirow[t]{2}{*}{$G D P$} & -.099 & -.157 & $-.173 *$ & -.061 & -.088 & -.123 \\
\hline & $(.122)$ & (.109) & $(.106)$ & $(.127)$ & $(.114)$ & (.119) \\
\hline \multirow[t]{2}{*}{$G D P^{2}$} & .115 & .162 & .169 & .008 & .034 & .116 \\
\hline & (.126) & (.113) & (.106) & $(.122)$ & (.106) & $(.121)$ \\
\hline $\mathrm{R}^{2}$ & .499 & .579 & .562 & .472 & .555 & .573 \\
\hline Obs. & 68 & 68 & 68 & 67 & 67 & 67 \\
\hline
\end{tabular}

The dependent variable is the average Gini coefficient between 1980 and 2000. Real per capita GDP and education (sec 25 and $g h \_15$ ) are in initial values, financial variables (smpr, smcap and privo) are in sample averages. All regressions include a dummy for Latin American countries. Coefficients are estimated with Ordinary Least Squares. Robust standard errors are reported in parenthesis, 5 and 10 per cent significant coefficients are marked with ** and *, respectively.

Table 2. Risk-sharing market, investor protection and income inequality OLS - cross-section - 1980-2000

\begin{tabular}{|c|c|c|c|}
\hline & 1 & 2 & 3 \\
\hline Investor_pr & $\begin{array}{c}.008^{*} \\
(.005)\end{array}$ & $\begin{array}{l}-.001 \\
(.005)\end{array}$ & $\begin{array}{l}-.009 * \\
(.005)\end{array}$ \\
\hline Smpr & & $\begin{array}{l}.101^{* *} \\
(.025)\end{array}$ & \\
\hline Smpr*investor_pr & & & $\begin{array}{l}.014 * * \\
(.002)\end{array}$ \\
\hline $\operatorname{Sec} 25$ & $\begin{array}{l}-.175^{* * *} \\
(.067)\end{array}$ & $\begin{array}{l}-.166^{* * *} \\
(.067)\end{array}$ & $\begin{array}{l}-.158 * * \\
(.067)\end{array}$ \\
\hline$G D P$ & $\begin{array}{l}-.167 \\
(.223)\end{array}$ & $\begin{array}{l}-.308 \\
(.183)\end{array}$ & $\begin{array}{l}-.338^{*} \\
(.183)\end{array}$ \\
\hline$G D P^{2}$ & $\begin{array}{l}.131 \\
(.238) \\
\end{array}$ & $\begin{array}{r}.286 \\
(.202) \\
\end{array}$ & $\begin{array}{c}.306 \\
(.197) \\
\end{array}$ \\
\hline $\mathrm{R}^{2}$ & .496 & .641 & .646 \\
\hline Obs. & 43 & 42 & 42 \\
\hline
\end{tabular}

The dependent variable is the average Gini coefficient between 1980 and 2000. Real per capita GDP and education (sec25 and $g h \_15$ ) are in initial values, smpr is in sample averages. All regressions include a dummy for Latin American countries. Coefficients are estimated with Ordinary Least Squares. Robust standard errors are reported in parenthesis, 5 and 10 per cent significant coefficients are marked with $* *$ and $*$, respectively. 
Table 3. Investor protection, risk-sharing market and income inequality

IV - cross-section - 1980-2000

\begin{tabular}{|c|c|c|c|}
\hline \multicolumn{4}{|c|}{ Panel A. First Step - Dependent variable: $s m p r$} \\
\hline \multirow{4}{*}{$\operatorname{Sec} 25$} & 1 & 2 & 3 \\
\hline & Whole sample & Smpr $<1.5$ & Whole sample \\
\hline & .031 & .246 & -.293 \\
\hline & $(.598)$ & $(.313)$ & $(.471)$ \\
\hline \multirow[t]{2}{*}{$G D P$} & .212 & .579 & 1.299 \\
\hline & $(1.016)$ & $(.545)$ & $(.941)$ \\
\hline \multirow[t]{2}{*}{$G D P^{2}$} & -.298 & -.539 & -1.597 \\
\hline & $(1.093)$ & $(.585)$ & $(1.039)$ \\
\hline Investor_pr & & & $\begin{array}{l}.097 * * \\
(.024)\end{array}$ \\
\hline Eff_jud & & & $\begin{array}{l}.047 \\
(.040)\end{array}$ \\
\hline UK legal origin & $\begin{array}{l}.588^{* *} \\
(.242)\end{array}$ & $\begin{array}{l}.419^{* *} \\
(.128)\end{array}$ & \\
\hline FR legal origin & $\begin{array}{l}.135 \\
(.269)\end{array}$ & $\begin{array}{l}.126 \\
(.141)\end{array}$ & \\
\hline GE legal origin & $\begin{array}{c}.017 \\
(.339)\end{array}$ & $\begin{array}{l}-.053 \\
(.177)\end{array}$ & \\
\hline $\mathrm{R}^{2}$ & .183 & .302 & .386 \\
\hline Obs. & 68 & 65 & 42 \\
\hline \multicolumn{4}{|c|}{ Panel B. Second Step-Dependent variable: Gini } \\
\hline & $\begin{array}{c}1 \\
\text { Whole sample }\end{array}$ & $\begin{array}{r}2 \\
\text { Smpr }<15\end{array}$ & $\begin{array}{c}3 \\
\text { Whole }\end{array}$ \\
\hline smpr & $\begin{array}{l}.109 * * \\
(.042)\end{array}$ & $\begin{array}{l}.136^{* * *} \\
(.047)\end{array}$ & $\begin{array}{l}.077 * * \\
(.038)\end{array}$ \\
\hline $\operatorname{Sec} 25$ & $\begin{array}{l}-.176^{* *} \\
(.077)\end{array}$ & $\begin{array}{l}-.201 * * \\
(.060)\end{array}$ & $\begin{array}{l}-.163 * * \\
(.067)\end{array}$ \\
\hline$G D P$ & $\begin{array}{l}-.082 \\
(.143)\end{array}$ & $\begin{array}{l}-.224^{*} \\
(.114)\end{array}$ & $\begin{array}{l}-.275^{*} \\
(.152)\end{array}$ \\
\hline$G D P^{2}$ & $\begin{array}{l}.102 \\
(.155) \\
\end{array}$ & $\begin{array}{r}.233^{*} \\
(.123) \\
\end{array}$ & $\begin{array}{c}.246 \\
(.173) \\
\end{array}$ \\
\hline Sargan (p-value) & .345 & .149 & .369 \\
\hline F-test & 3.98 & 7.08 & 9.44 \\
\hline (p-value) & .012 & .000 & .000 \\
\hline
\end{tabular}

Panel A. The dependent variable is average smpr between 1980 and 2000.

Real per capita GDP and education (sec25 and $g h \_15$ ) are in initial values, investor protection and efficiency of the judiciary are averages.

Panel B. The dependent variable is the average Gini coefficient between 1980 and 2000. Real per capita GDP and education (sec25 and $\left.g h \_15\right)$ are in initial values, smpr is in sample averages. Both p-values and statistics are reported for the F-test of the excluded instruments. Only p-values are reported for the Sargan test of overidentifying restrictions.

All regressions include a dummy for Latin American countries. Coefficients are estimated with Two-Stages Least Squares. Robust standard errors are reported in parenthesis, 5 and 10 per cent significant coefficients are marked with $* *$ and $*$, respectively. 
Table 4. Risk-sharing market and income inequality

Sensitivity analysis - cross-section - 1980-2000

\begin{tabular}{|c|c|c|c|c|c|c|}
\hline & \multicolumn{2}{|c|}{$\begin{array}{c}\text { OLS } \\
\text { Latest Gini } \\
\text { Average } s m p r\end{array}$} & \multicolumn{2}{|c|}{$\begin{array}{l}\text { IV - legal origins } \\
\text { Latest Gini } \\
\text { Average smpr } \\
\end{array}$} & \multicolumn{2}{|c|}{$\begin{array}{c}\text { OLS } \\
\text { Average Gini } \\
\text { smpr }(1985)\end{array}$} \\
\hline & $\begin{array}{c}1 \\
\text { Whole } \\
\text { sample }\end{array}$ & $\begin{array}{c}2 \\
\text { Whole } \\
\text { sample } \\
\end{array}$ & $\begin{array}{c}3 \\
\text { Whole } \\
\text { sample } \\
\end{array}$ & $\begin{array}{c}4 \\
\text { smpr } \\
<1.5 \\
\end{array}$ & $\begin{array}{c}5 \\
\text { Whole } \\
\text { sample } \\
\end{array}$ & $\begin{array}{c}6 \\
\text { Whole } \\
\text { sample } \\
\end{array}$ \\
\hline $\begin{array}{l}\text { Smpr } \\
S m p r^{2}\end{array}$ & $\begin{array}{l}.032 \\
(.031)\end{array}$ & $\begin{array}{l}.136 * * \\
(.035) \\
-.034 * * \\
(.009) \\
\end{array}$ & $\begin{array}{l}.109 * * \\
(.046)\end{array}$ & $\begin{array}{l}.131 * * \\
(.051)\end{array}$ & $\begin{array}{l}.087 * * \\
(.032)\end{array}$ & $\begin{array}{l}.040 \\
(.063) \\
.0003 \\
(.0004)\end{array}$ \\
\hline $\begin{array}{l}\mathrm{R}^{2} \\
\mathrm{~F}-\text {-Test } \\
\text { (p-value) } \\
\text { Sargan } \\
\text { (p-value) }\end{array}$ & .469 & .543 & $\begin{array}{l}.265 \\
3.900 \\
(.013) \\
1.786 \\
(.409)\end{array}$ & $\begin{array}{c}.541 \\
7.600 \\
(.000) \\
3.202 \\
(.202)\end{array}$ & .633 & .639 \\
\hline Obs. & 65 & 65 & 65 & 62 & 40 & 40 \\
\hline
\end{tabular}

In columns 1-4 the dependent variable is the latest available observation of

Gini coefficient after 1985, smpr is 1980-2000 average. Initial (1980) values of real per capita GDP and sec 25 plus a dummy for Latin America are included. In columns 5-6 the dependent variable is the 1985-2000 average of Gini, smpr is observed in 1985. Initial (1985) values of real per capita GDP and sec25 plus a dummy for Latin America are included. Coefficients in columns 1-2 and 5-6 are estimated with Ordinary Least Squares. Coefficients in columns 3-4 are second step estimates from 2SLS regressions, with legal origins as instruments for smpr, first step estimates are not reported but available from the author. Robust standard errors are reported in parenthesis, 5 and 10 per cent significant coefficients are marked with ** and *, respectively. 
Table 5. Risk-sharing market and income inequality

Robustness analysis - cross-section - 1980-2000

\begin{tabular}{|c|c|c|c|c|}
\hline & \multicolumn{2}{|c|}{ OLS } & \multicolumn{2}{|c|}{ IV - legal origins } \\
\hline & $\begin{array}{c}1 \\
\text { Whole } \\
\text { sample }\end{array}$ & $\begin{array}{c}2 \\
\text { Whole } \\
\text { sample }\end{array}$ & $\begin{array}{c}3 \\
\text { Whole } \\
\text { sample }\end{array}$ & $\begin{array}{c}4 \\
\text { smpr }<1.5\end{array}$ \\
\hline \multirow[t]{2}{*}{ Smpr } & .039 & $.158^{* *}$ & $.122 * *$ & $.165^{* *}$ \\
\hline & $(.032)$ & $(.037)$ & $(.049)$ & $(.058)$ \\
\hline Smpr $r^{2}$ & & $\begin{array}{l}-.037 * * \\
(.009)\end{array}$ & & \\
\hline \multirow[t]{2}{*}{ Gov } & -.0006 & -.001 & -.002 & -.0015 \\
\hline & (.0008) & (.0008) & $(.002)$ & $(.0011)$ \\
\hline \multirow[t]{2}{*}{ Trade } & .00001 & -.0002 & -.0002 & -.0003 \\
\hline & $(.0001)$ & $(.0002)$ & $(.0003)$ & (.0003) \\
\hline \multirow[t]{2}{*}{$\operatorname{Sec} 25$} & $-.186 * *$ & $-.207 * *$ & $-.185^{* *}$ & $-.220 * *$ \\
\hline & $(.057)$ & $(.054)$ & (.082) & $(.063)$ \\
\hline \multirow[t]{2}{*}{$G D P$} & -.111 & -.140 & -.069 & -.182 \\
\hline & $(.136)$ & $(.120)$ & $(.162)$ & $(.125)$ \\
\hline \multirow[t]{2}{*}{$G D P^{2}$} & .122 & .139 & .081 & .184 \\
\hline & $(.138)$ & $(.124)$ & $(.172)$ & $(.133)$ \\
\hline $\mathrm{R}^{2}$ & .502 & .592 & .264 & .571 \\
\hline F-Test & & & 3.18 & 5.45 \\
\hline (p-value) & & & $(.030)$ & $(.002)$ \\
\hline Sargan & & & 2.231 & 3.942 \\
\hline (p-value) & & & $(.328)$ & (.139) \\
\hline Obs. & 68 & 68 & 68 & 65 \\
\hline
\end{tabular}

The dependent variable is the average Gini coefficient between 1980 and 2000. Real per capita GDP and sec25 are in initial values, $s m p r$, government expenditure ( $g o v)$ and trade over GDP are in sample averages. All regressions include a dummy for Latin American countries. Coefficients in columns 1-2 are estimated with Ordinary Least Squares. Coefficients in columns 3-4 are second step estimates from 2SLS regressions, with legal origins as instruments for smpr; first step estimates are not reported but available from the author. Robust standard errors are reported in parenthesis, 5 and 10 per cent significant coefficients are marked with ** and ${ }^{*}$, respectively. 
Table 6. Risk-sharing market and income inequality

Static Panel - 1976-2000

\begin{tabular}{|c|c|c|c|c|c|c|}
\hline & \multicolumn{3}{|c|}{ Large sample } & \multicolumn{3}{|c|}{ DPD sample } \\
\hline & 1 & 2 & 3 & 4 & 5 & 6 \\
\hline & $\mathrm{RE}$ & $\mathrm{FE}$ & $\mathrm{RE}$ & RE & $\mathrm{RE}$ & RE \\
\hline Smpr & $2.615^{* *}$ & $2.88^{*}$ & & $3.368 * *$ & $7.430 * *$ & \\
\hline & $(.551)$ & (1.62) & & $(1.059)$ & (2.389) & \\
\hline$S m p r^{2}$ & & $\begin{array}{l}-.023 \\
(.259)\end{array}$ & & & $\begin{array}{l}-1.983^{*} \\
(1.036)\end{array}$ & \\
\hline Smcap & & & $\begin{array}{l}17.449 * * \\
(3.886)\end{array}$ & & & $\begin{array}{l}6.579 * * \\
(1.760)\end{array}$ \\
\hline Privo & & & $\begin{array}{l}-5.358^{* * *} \\
(1.899)\end{array}$ & & & $\begin{array}{l}-3.097 \\
(2.472)\end{array}$ \\
\hline $\operatorname{Sec} 25$ & $\begin{array}{l}-.177 * * \\
(.049)\end{array}$ & $\begin{array}{l}-.149 * * \\
(.068)\end{array}$ & $\begin{array}{l}-.206^{* * *} \\
(.049)\end{array}$ & $\begin{array}{l}-.180 * * \\
(.050)\end{array}$ & $\begin{array}{l}-.198 * * \\
(.050)\end{array}$ & $\begin{array}{l}-.161^{* *} \\
(.048)\end{array}$ \\
\hline$G D P$ & $\begin{array}{l}-12.923^{*} \\
(7.151)\end{array}$ & $\begin{array}{l}-7.803 \\
(.11 .89)\end{array}$ & $\begin{array}{l}-14.892 * * \\
(7.196)\end{array}$ & $\begin{array}{l}-9.053 \\
(7.181)\end{array}$ & $\begin{array}{l}-9.107 \\
(7.011)\end{array}$ & $\begin{array}{l}-10.417 \\
(7.439)\end{array}$ \\
\hline$G D P^{2}$ & $\begin{array}{l}10.839 * * \\
(4.838)\end{array}$ & $\begin{array}{l}8.795 \\
(6.443)\end{array}$ & $\begin{array}{l}9.369 * * \\
(4.774)\end{array}$ & $\begin{array}{c}9.054 * \\
(4.686)\end{array}$ & $\begin{array}{c}8.875^{*} \\
(4.651)\end{array}$ & $\begin{array}{l}8.368^{*} \\
(4.652)\end{array}$ \\
\hline Hausman test & .425 & .026 & .951 & .461 & .248 & .369 \\
\hline Countries & 50 & 50 & 50 & 34 & 34 & 34 \\
\hline Obs. & 144 & 144 & 144 & 112 & 112 & 112 \\
\hline
\end{tabular}

The dependent variables is the Gini coefficient. Real per capita GDP, and education ( $\sec 25)$ are in initial values, financial variables (smpr, smcap and privo) are in sample averages over non-overlapping 5-year periods. All equations were estimated with random (RE) and fixed effects (FE). The coefficients are reported from the specification chosen based on the Hausman tests, whose p-values are reported in the table. Robust standard errors are reported in parenthesis, 5 and 10 per cent significant coefficients are marked with ** and *, respectively. 
Table 7. Risk-sharing market and income inequality Dynamic Panel Data - System GMM - 1976-2000

\begin{tabular}{|c|c|c|c|c|c|c|}
\hline \multirow[b]{2}{*}{$\log (S m p r)$} & 1 & 2 & 3 & 4 & $\overline{5}$ & 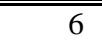 \\
\hline & $.045^{* *}$ & $.041^{* *}$ & $.204 * *$ & $.128 *$ & & \\
\hline & $(.021)$ & $(.021)$ & $(.071)$ & $(.068)$ & & \\
\hline \multirow[t]{2}{*}{$\log \left(S m p r^{2}\right)$} & & & $-.119 * *$ & -.061 & & \\
\hline & & & $(.054)$ & $(.054)$ & & \\
\hline \multirow[t]{2}{*}{$\log ($ Smcap $)$} & & & & & $.106 * *$ & $.095 * *$ \\
\hline & & & & & $(.029)$ & $(.034)$ \\
\hline \multirow[t]{2}{*}{$\log$ (Privo) } & & & & & $-.106^{* *}$ & $-.131 * *$ \\
\hline & & & & & $(.041)$ & $(.037)$ \\
\hline \multirow[t]{2}{*}{$\log ($ Gini_5) } & $.369 * *$ & $.387 * *$ & $.361 * *$ & $.441 * *$ & $.379 * *$ & $.445 * *$ \\
\hline & $(.151)$ & $(.144)$ & $(.139)$ & $(.132)$ & $(.181)$ & $(.164)$ \\
\hline \multirow[t]{2}{*}{$\log (\operatorname{Sec} 25)$} & -.081 & -.095 & -.105 & -.069 & -.117 & -.134 \\
\hline & $(.104)$ & $(.083)$ & $(.079)$ & $(.069)$ & $(.095)$ & $(.103)$ \\
\hline \multirow[t]{2}{*}{$\log (G D P)$} & .188 & .249 & .166 & .274 & .161 & $.320 *$ \\
\hline & $(.174)$ & $(.170)$ & $(.168)$ & $(.167)$ & (.158) & $(.176)$ \\
\hline \multirow[t]{2}{*}{$\log \left(G D P^{2}\right)$} & -.211 & -.280 & -.198 & -.322 & -.146 & -.287 \\
\hline & $(.206)$ & $(.204)$ & (.189) & (.196) & $(.177)$ & $(.187)$ \\
\hline Sargan (p-value) & .387 & .506 & .793 & .776 & .508 & .647 \\
\hline $\mathrm{m}_{2}(\mathrm{p}$-value $)$ & .527 & .870 & .383 & .822 & .346 & .481 \\
\hline $\begin{array}{l}\text { Time FE } \\
\text { (F-Test) }\end{array}$ & No & $\begin{array}{l}\text { Yes } \\
(.153)\end{array}$ & No & $\begin{array}{l}\text { Yes } \\
(.293)\end{array}$ & No & $\begin{array}{l}\text { Yes } \\
(.123)\end{array}$ \\
\hline Countries & 32 & 32 & 32 & 32 & 32 & 32 \\
\hline Obs. & 84 & 84 & 84 & 84 & 84 & 84 \\
\hline
\end{tabular}

The dependent variables in the system are the log and the log-difference of the Gini coefficient. All regressors are in log and logdifferences. Real per capita GDP, and education (sec25) are in initial values, financial variables (smpr, smcap and privo) are in sample averages over non-overlapping 5-year periods. Coefficients are first step estimates from 2-step system GMM regressions à la Arellano and Bover, performed with PcGive. All regressors are treated as endogenous (Gini) or predetermined, hence instrumented. Lagged levels are used as instruments for differences, and lagged differences as instruments for levels. Robust (first step) standard errors are reported in parenthesis, 5 and 10 per cent significant coefficients are marked with ** and *, respectively. P-values for the Sargan and $\mathrm{m}_{2}$ tests are reported from the second step. 
Table 8. Risk-sharing market and income inequality Robustness analysis - Panel - 1976-2000

\begin{tabular}{|c|c|c|c|c|c|c|}
\hline & \multicolumn{2}{|c|}{ Static Panel-RE } & \multicolumn{4}{|c|}{ Dynamic Panel - System GMM } \\
\hline & 1 & 2 & 3 & 4 & 5 & 6 \\
\hline \multirow[t]{2}{*}{ Smpr } & $2.858^{* *}$ & $6.683^{* *}$ & $.047 * *$ & $.168^{* *}$ & $.057 * *$ & $.189 * *$ \\
\hline & (1.139) & (2.411) & $(.020)$ & $(.068)$ & $(.022)$ & $(.069)$ \\
\hline \multirow[t]{2}{*}{ Smpr ${ }^{2}$} & & $-1.865^{*}$ & & $-.093 *$ & & $-.099 *$ \\
\hline & & $(1.031)$ & & $(.051)$ & & $(.053)$ \\
\hline \multirow[t]{2}{*}{ Gov } & .066 & .059 & -.009 & -.004 & & \\
\hline & $(.089)$ & $(.087)$ & $(.087)$ & $(.077)$ & & \\
\hline \multirow[t]{2}{*}{ Trade } & .024 & .022 & & & -.028 & $-.034 *$ \\
\hline & $(.017)$ & $(.016)$ & & & $(.024)$ & $(.019)$ \\
\hline \multirow[t]{2}{*}{ Gini_5 } & & & $.347 * *$ & $.367 * *$ & $.390 * *$ & $400 * *$ \\
\hline & & & $(.149)$ & $(.133)$ & $(.143)$ & $(.140)$ \\
\hline \multirow[t]{2}{*}{$\operatorname{Sec} 25$} & $-.174 * *$ & $-.189 * *$ & -.088 & -.092 & $-.139 * *$ & $-.163^{* *}$ \\
\hline & $(.050)$ & $(.050)$ & $(.072)$ & $(.071)$ & $(.064)$ & $(.067)$ \\
\hline \multirow[t]{2}{*}{$G D P$} & -10.074 & -10.070 & .189 & .196 & .219 & .169 \\
\hline & (7.363) & $(7.214)$ & $(.171)$ & $(.166)$ & $(.168)$ & $(.143)$ \\
\hline \multirow[t]{2}{*}{$G D P^{2}$} & $9.576^{* *}$ & $9.353 * *$ & -.211 & -.232 & -.214 & -.169 \\
\hline & $(4.667)$ & $(4.636)$ & $(.196)$ & $(.183)$ & $(.194)$ & $(.171)$ \\
\hline Hausman & .325 & .118 & & & & \\
\hline Sargan (p-value) & & & .584 & .896 & .808 & .967 \\
\hline $\mathrm{m}_{2}(\mathrm{p}$-value $)$ & & & .504 & .393 & .414 & .386 \\
\hline Countries & 34 & 34 & 32 & 32 & 32 & 32 \\
\hline Obs. & 112 & 112 & 84 & 84 & 84 & 84 \\
\hline
\end{tabular}

The dependent variable is the 5-year average Gini coefficient. Real per capita GDP and sec25 are in initial values, smpr, government expenditure (gov) and trade over GDP are in 5-year averages. All regressions include a dummy for Latin American countries. All variables are in levels in columns 1-2, in logs and logdifferences in columns 3-6. Coefficients in columns 1-2 are estimated with random effects (preferred to fixed effects on the basis of the Hausman test). Coefficients in columns 3-4 are first step estimates from 2-step system GMM regressions à la Arellano and Bover, performed with PcGive. All regressors are treated as endogenous (Gini) or predetermined, hence instrumented. Lagged levels are used as instruments for differences and lagged differences as instruments for levels. Robust standard errors (from the first step, in columns 3-6) are reported in parenthesis, 5 and 10 per cent significant coefficients are marked with ** and *, respectively. P-values for the Sargan and $\mathrm{m}_{2}$ tests are reported from the second step. 